\title{
GOVERNANÇA TERRITORIAL: o que avançou com o Estatuto da Metrópole?
}

\author{
Angela Moulin Simões Penalva Santos ${ }^{1}$ \\ Maria Rita Rodrigues ${ }^{2}$ \\ Thiago Serp ${ }^{3}$ \\ Carlos Humberto Francisco de Souza ${ }^{4}$ \\ Ethiene Vanila de Souza Wencela ${ }^{5}$ \\ Carlos Eduardo de Souza Cruz $^{6}$
}

\section{Resumo}

O surgimento de novos arranjos territoriais, como as regiões metropolitanas, enseja o enfrentamento de muitos desafios que se colocam à consecução de uma gestão urbana adequada ao desenvolvimento das cidades. O advento do Estatuto da Metrópole, Lei no 13.089/2015, é identificado como relevante avanço normativo para a indução da governança de territórios não reconhecidos como entes federados. Resultando dos trabalhos desenvolvidos pelo grupo de pesquisa institucional "Governança Territorial Urbana e Relações Interfederativas", no âmbito da linha de pesquisa em Direito da Cidade do Programa de Pós-Graduação em Direito da UERJ, o artigo propõe-se a analisar desdobramentos da entrada em vigor do Estatuto da Metrópole para a governança de regiões metropolitanas. Por meio de pesquisa bibliográfica e de coleta e análise de dados, foram investigadas mudanças institucionais em regiões metropolitanas que têm como núcleo capitais estaduais, procurando-se avaliar ainda a disseminação da temática relativa à governança urbano-territorial entre especialistas. Apesar da crescente disseminação dessa temática, verificou-se que a concentração regional de sua produção acadêmico-científica pode comprometer seu entendimento em termos

\footnotetext{
1 Pós Doutora em Arquitetura e Urbanismo pela USP, Professora da Faculdade de Ciências Econômicas e do Programa de Pós-Graduação em Direito da UERJ. Instituição: Universidade do Estado do Rio de Janeiro - UERJ, Rio de Janeiro. Brasil. E-mail: penalvasantosangela@gmail.com ${ }^{2}$ Doutoranda e Mestra em Direito pela Universidade do Estado do Rio de Janeiro (UERJ). Pós graduanda lato sensu em Direito, Políticas Públicas e Controle Externo pela Universidade Nove de Julho (UNINOVE). Instituição: Universidade do Estado do Rio de Janeiro - UERJ, Rio de Janeiro. Brasil. E-mail: mariarita.rdg@gmail.com ${ }^{3}$ Doutorando em Direito da Cidade pela UERJ. Instituição: Universidade do Estado do Rio de Janeiro - UERJ, Rio de Janeiro. Brasil. E-mail: thiagoerthal@yahoo.com.br

${ }^{4}$ Mestrando em Direito da Cidade pela UERJ. Instituição: Universidade do Estado do Rio de Janeiro - UERJ, Rio de Janeiro. Brasil. E-mail: carloshfsouza@uol.com.br

${ }^{5}$ Mestranda em Direito da Cidade pela UERJ, bolsista Capes. Instituição: Universidade do Estado do Rio de Janeiro - UERJ, Rio de Janeiro. Brasil. E-mail: ethiene-wenceslau@outlook.com

${ }^{6}$ Mestrando em Direito da Cidade pela UERJ, bolsista CNPQ. Instituição: Universidade do Estado do Rio de Janeiro - UERJ, Rio de Janeiro. Brasil. E-mail: carloseduardosc@gmail.com
} 
nacionais. Constatou-se também pouco avanço institucional decorrente do Estatuto da Metrópole nas regiões metropolitanas analisadas, à vista dos Planos de Desenvolvimento Urbano Integrado e das agências metropolitanas de gestão territorial.

Palavras-chave: Regiões metropolitanas; Estatuto da Metrópole; Governança territorial, Plano de Desenvolvimento Urbano Integrado; Agência metropolitana.

\section{Gobernanza Territorial: ¿Qué avanzó con el Estatuto de la Metrópoli?}

\section{Resumen}

El surgimiento de nuevos arreglos territoriales, como las regiones metropolitanas, plantea el enfrentamiento de desafíos para la consecución de una gestión urbana adecuada al desarrollo de las ciudades. El advenimiento del Estatuto de la Metrópoli, Ley ํo 13.089 / 2015, es identificado como relevante avance normativo para inducir la gobernanza de territorios no reconocidos como entes federados. Resultando de trabajos desarrollados por el grupo de investigación "Gobernanza Territorial Urbana y Relaciones Interfederativas" en el marco del Programa de Post-Graduación en Derecho de la UERJ, el artículo analiza los desdoblamientos del Estatuto de la Metrópoli para la gobernanza de regiones metropolitanas. Por medio de investigación bibliográfica y de recolección y análisis de datos, se investigaron cambios institucionales en regiones metropolitanas que tienen como núcleo capitales estaduales, buscando evaluar la diseminación de la temática relativa a la gobernanza urbano-territorial entre especialistas. A pesar de la creciente diseminación de esta temática, se verificó que la concentración regional de su producción académico-científica puede comprometer su entendimiento en términos nacionales. Se constató también poco avance institucional resultante del Estatuto de la Metrópolis en las regiones metropolitanas analizadas, a la vista de los Planes de Desarrollo Urbano Integrado y de las agencias metropolitanas de gestión territorial.

Palabras clave: Regiones metropolitanas; Estatuto de la Metrópoli; Gobernanza territorial, Plan de Desarrollo Urbano Integrado; Agencia metropolitana.

Territorial Governance: what progress has been made with the Metropolis Statute?

\section{Abstract}


The emergence of new territorial arrangements, such as the metropolitan regions, gives rise to certain challenges in achieving adequate urban management for cities development. The Metropolis Statute, Law No. 13,089/2015, has been identified as a relevant regulatory advance in order to induce the governance of territories not recognised as federated entities. Resulting of the institutional research group "Urban Territorial Governance and Interfederative Relations" created by the UERJ Postgraduate Law Programme, the article analyses some developments of the Metropolis Statute's entry into force for the governance of metropolitan territories. Through bibliographic research and data collection and analysis, institutional changes were investigated in metropolitan regions that have state capitals as their nuclei, in an attempt to review the progress towards rules that were established by the Metropolis Statute, being also investigated the dissemination of the theme related to urban-territorial governance among specialists. In spite of the increasing dissemination of this theme, it was verified that the regional concentration of its academic-scientific production can compromise its understanding in national terms. There was also little institutional progress from the Metropolis Statute in the metropolitan regions analyzed, in view of the Integrated Urban Development Plans and metropolitan agency for territorial management.

Keywords: Metropolitan regions; Metropolis Statute; Territorial governance, Integrated Urban Development Plan; Metropolitan agency.

\section{Introdução}

A investigação sobre os desafios da política urbana no contexto federativo brasileiro avançou desde a abordagem municipalista, característica do período pós-constitucional, até o reconhecimento da necessidade de maior participação dos governos estaduais no ordenamento do território. Nesse quadro, a lei que instituiu o Estatuto da Metrópole constitui importante avanço normativo na indução à cooperação interfederativa para o planejamento, a gestão e a execução das funções públicas de interesse comum em espaços metropolitanos, ainda que não tenha sido capaz de prover fontes adequadas de financiamento, tornando a expectativa da cooperação difícil de ser concretizada.

Os desafios da gestão urbana, em face da emergência de novas formas de ordenamento territorial, como é o caso das regiões metropolitanas, foram objeto de investigação no âmbito do grupo de pesquisa institucional "Governança Territorial Urbana e Relações Interfederativas", realizado pelo Programa de Pós-Graduação em Direito da Universidade do Estado do Rio de Janeiro (PPGD/UERJ), na linha de pesquisa em Direito da Cidade. Decorrente dessa investigação, este artigo focaliza as regiões 
metropolitanas que têm como núcleo capitais estaduais, visando, por meio de pesquisa bibliográfica e de coleta e análise de dados:

- pesquisar a disseminação entre especialistas do tema da governança territorial metropolitana: i) nos documentos que sintetizam a abordagem da Agência Habitat/ONU em seus três encontros, realizados em 1976, 1996 e 2016; ii) em recentes anais do Encontro Nacional da Associação Nacional de Pós-Graduação e Pesquisa em Planejamento Urbano e Regional (ENANPUR) e do Encontro Nacional da Associação Nacional de Pós-Graduação e Pesquisa em Administração (EnANPAD); iii) em artigos publicados pela Revista de Direito da Cidade e pela Revista Brasileira de Estudos Urbanos e Regionais (RBEUR) no período entre 2015 e 2017;

- realizar um balanço do avanço resultante de regras estabelecidas pelo Estatuto da Metrópole, considerando-se, sobretudo, a necessidade de elaboração do Plano Diretor Urbano Integrado e da agência metropolitana de gestão territorial.

Acerca da disseminação da temática relativa à governança urbano-territorial entre especialistas, dois objetos de análise foram selecionados: o primeiro deles, de âmbito internacional, se refere ao acordado nas conferências do Programa das Nações Unidas para os Assentamentos Humanos, comumente conhecido como ONU-Habitat, na medida em que essas conferências congregam amplas discussões sobre o espaço urbano, sendo realizadas por representantes dos países-membros, incluindo muitos especialistas, como gestores públicos, pesquisadores e doutrinadores. O segundo objeto de análise, por apresentar significativa projeção nacional, trata-se da produção acadêmico-científica decorrente dos últimos ENANPUR e EnANPAD, assim como da produção referente às últimas edições da Revista de Direito da Cidade e da Revista Brasileira de Estudos Urbanos e Regionais (RBEUR), justamente no período que compreende a entrada em vigor do Estatuto da Metrópole.

$\mathrm{O}$ artigo encontra-se estruturado em seis seções, sendo a primeira delas esta introdução. $\mathrm{Na}$ segunda seção, realiza-se uma análise acerca de problemas enfrentados para a cooperação interfederativa na gestão dos territórios metropolitanos. Na terceira, o foco volta-se à disseminação da temática relativa à governança urbano-territorial entre especialistas, que são responsáveis pela entrada do tema na agenda das políticas públicas territoriais. A quarta seção é dedicada à evolução do avanço normativo quanto à cooperação para a governança territorial. Por sua vez, na quinta, elabora-se um balanço sobre avanços institucionais nas regiões metropolitanas analisadas, considerando-se a normatividade instituída pelo Estatuto da Metrópole. A sexta e última seção compreende as considerações finais.

\section{Situando o desafio da governança metropolitana}


A edição da Lei no 13.089/2015, conhecida como o Estatuto da Metrópole, foi festejada como um importante avanço normativo para induzir adequadamente a governança de territórios que não são reconhecidos como entes federativos, como é o caso das regiões metropolitanas. Estas já tinham sido reconhecidas como territórios que demandavam gestão interfederativa, desde que foram instituídas na década de $1970^{1}$. Nesta ocasião, foram criados, em cada uma delas, órgãos de gestão metropolitana, responsáveis pelo planejamento e execução dos serviços de interesse comum dos municípios que as constituíam.

Tratava-se de uma estratégia de um governo autoritário num contexto em que vigia grande confiança na capacidade do Estado de dar efetividade a seu macroplanejamento. Mas o êxito dessa experiência foi muito desigual, sobressaindo-se os casos das regiões metropolitanas de Belo Horizonte e São Paulo como as mais bem-sucedidas, ainda que longe de atingir os objetivos do planejamento metropolitano, segundo pesquisa do Instituto de Pesquisa Econômica Aplicada (IPEA) sobre os 40 anos de existência das regiões metropolitanas (COSTA \& TSUKUMO, 2013).

Com a redemocratização e a entrada em vigor da Constituição de 1988, as regiões metropolitanas deixaram de ser criadas pelo governo federal, passando para a competência dos governos estaduais. Mas, ao mesmo tempo, os municípios deixaram de ser tutelados pelos Estados e foram alçados à condição de entes federativos. Em tais condições, a governança destes territórios passou a depender de maior cooperação voluntária entre os entes federativos. A maior fragmentação territorial advinda da criação de aproximadamente 1.500 municípios desde a década de 1980 só faria elevar o desafio da governança territorial.

Considerando as regiões metropolitanas existentes em 2018 e que tinham por núcleo uma capital estadual, verificamos que 375 municípios faziam parte de alguma destas regiões metropolitanas. Destaque deve ser concedido ao Sudeste, onde os quatro Estados tinham suas capitais nucleando regiões metropolitanas constituídas de 101 municípios, alcançando o percentual de 51,3\% da população daquela que é a região mais rica do país (SANTOS, 2018). Nessas circunstâncias, é imperativo que os planos diretores das capitais sejam elaborados em linha com o planejamento urbano-territorial dos demais municípios que fazem parte do mesmo território metropolitano.

Mas, como estimular a cooperação interfederativa entre entes considerados igualmente autônomos do ponto de vista jurídico, ainda que muito desiguais em termos econômicos e demográficos?

Tal objetivo vai além da dimensão administrativa da gestão pública para avançar em direção à governança urbano-territorial. A governança urbano-territorial torna o gestor um dentre um conjunto de atores atuantes, os quais devem incluir entidades, empresas, organizações não-governamentais. 0 poder público deixa de ser o protagonista exclusivo, e a participação popular e as relações com o 
mercado se impõem. Torna-se necessário, assim, a criação de instâncias de discussão e resolução de conflitos, o que foi reconhecido pelo Estatuto da Metrópole ao prever a criação de agências metropolitanas.

Antes disso, porém, a cooperação voluntária já era estimulada pela possibilidade de consorciamentos ou convênios. Em 2005, a Lei federal no 11.107/2005 conferiu maior segurança jurídica aos consórcios públicos, ao passo em que os convênios com a União experimentaram crescimento ao longo da última década, em função das políticas nacionais de saneamento, mobilidade urbana e habitação de interesse social. Ainda assim, a governança dos territórios metropolitanos é muito incipiente.

A abordagem institucionalista, em sua vertente da Teoria da Ação Coletiva, explica tal dificuldade analisando as motivações de grupos com interesses diversos (OLSON, 1965). Se os indivíduos e grupos de interesse se pautassem pela racionalidade em suas ações, a cooperação iria impor-se no caso dos serviços de interesse comum. No entanto, os oportunistas ("free riders") visam a se aproveitar da ação coletiva sem incorrer nos custos destas ações. Em tais condições, mesmo que os interesses comuns dos grupos sejam consensuais, pode não haver cooperação.

Cabe discutir, assim, como a ação coletiva pode ser estimulada e quais os mecanismos de coordenação deveriam ser criados. Estes poderiam ser positivos, como no caso dos planos nacionais que oferecem fundos para financiar uma dada política, ou negativos, sob a forma de coerção sobre os membros que não cooperam, como definiu a Ação Direta de Inconstitucionalidade (ADI) 1842, que analisou a lei fluminense que criou a região metropolitana do Rio de Janeiro (Relator Min. Luiz Fux, Relator p/ Acórdão Min. Gilmar Mendes, Tribunal Pleno, julgado em 06/03/2013, publicado em 16/09/2013). Vale dizer, o poder público pode cumprir um papel importante na indução à cooperação interfederativa, derivando-se daí uma Teoria da Ação Institucional Coletiva.

De acordo com Garson (2009, p. 439),

os governos seriam organizações que se engajariam - ou não - em ações coletivas com o objetivo de obter um benefício que não alcançariam através da ação individual. Para isso, eles avaliariam os benefícios que aufeririam da ação coordenada e os custos a incorrer e cooperariam quando os benefícios esperados fossem maiores que os custos de negociar, monitorar e fazer cumprir contratos políticos que se firmariam entre os governos.

Como no caso da Teoria da Ação Coletiva, também na Teoria da Ação Institucional Coletiva os grupos menores e mais organizados tendem a ter mais êxito, especialmente se contarem com um líder forte na condução da ação coletiva. Este justamente é um problema grave no federalismo brasileiro, composto pela União, 26 Estados, o Distrito Federal e mais 5.570 municípios. Estes últimos são prestadores de serviços à população e deveriam beneficiar-se de acordos firmados entre eles para 
compartilhar custos e benefícios desses serviços, especialmente daqueles serviços cuja produção depende de uma elevada escala para dar viabilidade econômica, como é o caso dos serviços de saneamento.

Mais do que os Estados, os municípios apresentam uma forte heterogeneidade em termos de peso econômico e porte demográfico, o que se reflete em prioridades distintas para atendimento de preferências diversas, dificultando a ação coletiva coordenada entre eles. As capitais estaduais poderiam ser líderes de redes federativas para governança territorial, mas esta não tem sido a experiência, destacando-se negativamente o Rio de Janeiro, que não teria tomado nenhuma iniciativa nesta direção, segundo pesquisa realizada junto a gestores da política urbana desde a entrada em vigor da Constituição até 2016 (SANTOS, 2017).

A indução governamental à cooperação interfederativa, presente no Estatuto da Metrópole, não pode prescindir de atores privados que tenham interesse em negócios que ultrapassem as fronteiras de um município. A parceria público-privada, entretanto, torna imprescindível a atividade regulatória por parte do governo e a participação popular para evitar a excessiva mercantilização dos serviços públicos, o que acabaria por excluir os pobres do acesso a tais serviços.

Diferente do ambiente institucionalmente autoritário em que foram criadas as primeiras regiões metropolitanas, aquelas criadas após 1988 foram iniciativas de leis estaduais e demandam cooperação voluntária entre os entes que as compõem: o governo estadual e as prefeituras dos seus municípios. Ao longo do período pós-constitucional, a experiência não foi positiva, por isso foram sendo elaboradas alterações legislativas que resultaram na edição do Estatuto da Metrópole, estabelecendo critérios para definição de metrópoles e condições para sua gestão plena, além da obrigatoriedade de elaboração de planos diretores urbanos integrados.

\section{A cooperação para a governança metropolitana: o olhar dos especialistas}

O crescimento dos espaços metropolitanos, particularmente a partir da segunda metade do século passado, passou a desafiar a política urbana e territorial daqueles países que viram acentuar a complexidade das questões associadas a seus processos de urbanização concentrada. Nesse contexto, o tema das relações interfederativas e governança territorial emergiria progressivamente como um dos aspectos sensíveis a envolver os debates e as ações sociopolíticas e institucionais voltadas ao fenômeno das regiões metropolitanas e dos aglomerados urbanos em geral.

A disseminação da temática relativa à cooperação interfederativa metropolitana pode ser avaliada, por certo, em diferentes âmbitos, mas o olhar dos especialistas a seu respeito demonstra particular importância para a adequada compreensão do estágio em que ela se encontra. Para tanto, 
dois objetos de análise foram selecionados: o primeiro deles, de âmbito internacional, se refere ao acordado nas conferências do Programa das Nações Unidas para os Assentamentos Humanos, comumente conhecido como ONU-Habitat, na medida em que elas congregam amplas discussões sobre o espaço urbano que são realizadas por representantes dos países-membros, dentre eles muitos especialistas. O segundo objeto de análise, por apresentar significativa projeção nacional, trata-se da produção acadêmico-científica decorrente dos últimos ENANPUR e EnANPAD, assim como da produção referente às últimas edições da Revista de Direito da Cidade e da Revista Brasileira de Estudos Urbanos e Regionais (RBEUR).

\subsection{ONU-HABITAT}

A disseminação do tema sobre as relações interfederativas e governança territorial, no âmbito das conferências do Programa das Nações Unidas para os Assentamentos Humanos (ONU-Habitat), evidencia o gradual ganho de importância das questões que envolvem as relações entre distintas instâncias de governo e a adequada organização e gestão urbano-territorial. Não deve surpreender que, ao tratar da política de assentamentos, a Declaração de Vancouver, principal documento produzido na Habitat I, em 1976, tenha sido praticamente silente sobre as questões intergovernamentais. Em verdade, essas questões dificilmente poderiam constituir preocupação central para aquela que foi a primeira conferência internacional sobre a temática urbana, momento em que a comunidade internacional apenas começava a encaminhar a discussão sobre os problemas decorrentes da intensa urbanização, inclusive com certo viés antiurbano à época (ANTONUCCl et al, 2010).

De todo modo, é possível conceber questionamentos iniciais, na Habitat I, referentes aos problemas da centralização e do dirigismo estatal para o desenvolvimento econômico e para a governança urbana, o que pode ser considerado como contexto em que as preocupações de ordem intergovernamental iriam consolidar-se. Nesse sentido, a Declaração de Vancouver propugnou pela abertura governamental à participação social, além de ter orientado governos centrais a auxiliarem autoridades locais a contribuírem para o desenvolvimento nacional, conforme estabeleceram os itens I - 1 (c), II - 13 e III - 10 do referido documento. Já no Plano de Ação de Vancouver é possível verificar maior profundidade sobre as questões que envolvem diferentes níveis de governo e a política urbanoterritorial. Em diversos momentos, o Plano menciona a necessidade de coordenação, harmonização e cooperação entre instâncias nacionais de governo para a promoção dos princípios e dos objetivos assumidos na Habitat I. Na seção sobre instituições e gerenciamento do Plano, por exemplo, enfatizouse a necessidade de estabelecerem-se mecanismos e instituições em diversos níveis, que, ao atuarem em conjunto, poderiam conferir abrangência nacional às ações de governança urbana. Por sua vez, na 
seção dedicada ao planejamento regional sobre áreas metropolitanas, recomendou-se uma abordagem integrada sobre esse tipo espacial, que requer coordenação entre diferentes agentes para a adequada provisão de alimentos, água, energia e transportes, assim como para a oferta de saneamento básico, controle de poluentes e serviços de saúde e de educação.

Apesar disso, a análise do Plano de Ação de Vancouver sugere que as questões intergovernamentais eram ainda bastante marginais, quando comparadas à centralidade atribuída a outros temas. Também se depreende a existência de uma perspectiva ainda marcadamente verticalizada sobre essas questões, perspectiva que confere proeminência aos entes centrais, e não locais ou regionais, em matéria de planejamento, elaboração e de execução de políticas urbanoterritoriais.

Vinte anos mais tarde, na Habitat II, realizada em Istambul, em 1996, evidenciou-se maior ênfase quanto às questões político-institucionais, em que se insere o tema das relações intergovernamentais. Comparada à primeira Habitat, que se encontrava muito detida ao processo da intensa urbanização em si, houve enfática defesa da reformulação da organização do Estado, no sentido da valorização da atuação dos demais atores públicos e privados no espaço urbano. Nesse sentido, observa-se a defesa da descentralização administrativa e dos poderes locais, do protagonismo das cidades e das responsabilidades compartilhadas entre distintas instâncias do Poder Público e a sociedade civil para a adequada formulação e execução das políticas urbanas.

Logo em seu primeiro item, inclusive, a Declaração de Istambul propõe a cooperação nos âmbitos nacionais e locais para a melhoria das condições de vida no espaço habitável. Ainda mais preciso é o item 12 do documento, em que se reconhecem as autoridades locais como "parceiros essenciais" para a implementação dos princípios e dos objetivos acordados na conferência. Influenciada pela Conferência das Nações Unidas sobre o Meio Ambiente e o Desenvolvimento (Rio 92), a própria Habitat II contou com maior diversificação de atores presentes ao encontro, com destaque para a participação de prefeitos e de outras autoridades locais junto a chefes de Estado, o que sinalizava efetivamente um novo contexto em que seriam encaminhadas as questões urbanas (ANTONUCCI et al, 2010).

Ao consagrar a descentralização e a valorização dos poderes locais, a Habitat II conferiu relevância à atuação das cidades, e não das entidades nacionais de governo. Em face das particularidades locais, reconheceu-se a importância do estabelecimento de diferentes níveis e tipos de cooperação para o enfrentamento dos problemas urbano-ambientais. Ainda que não se falasse especificamente sobre cooperação intergovernamental, na forma de uma diretriz consolidada e especificada, a diversificação de parcerias foi tida como fundamental para a implementação da Agenda Habitat, aprovada na ocasião, consistindo em conjunto de estratégias para que os países possam 
superar os desafios da urbanização. A tônica da Agenda Habitat, no que se refere ao desenvolvimento institucional, encontra-se justamente na defesa da descentralização administrativa e de uma governança urbana aberta à participação social, diferenciando-se do Plano de Ação de Vancouver, por exemplo, pela maior profundidade, ênfase e maior desenvoltura com que trata sobre a necessidade de promover a atuação de diferentes instâncias de governo, em particular as autoridades locais, na gestão urbano-territorial. A perspectiva sobre a organização administrativa estatal, em 1996, é menos verticalizada do que a da conferência anterior, o que evidencia a crescente valorização das esferas subnacionais como atores indispensáveis ao avanço das questões urbanas.

A recente Habitat III, sediada em Quito, em 2016, firmou a chamada Nova Agenda Urbana, consolidando o avanço de duas décadas das discussões urbano-territoriais em âmbito internacional. Uma análise de suas diretrizes aponta para a efetiva consolidação do tema relativo à articulação entre governos subnacionais e nacionais como importante característica do desenvolvimento institucional necessário à consecução dos objetivos assumidos pelos países-membros da conferência. Sendo assim, a coordenação intergovernamental em matéria de políticas públicas urbanas, de fato, passa a constituir uma das estratégias centrais defendidas pela nova Habitat.

No texto final da conferência, em que estão previstos a Declaração de Quito sobre Cidades Sustentáveis e Assentamentos Humanos para Todos e o Plano de Implementação para a Nova Agenda Urbana, o tema relativo à cooperação entre todos os níveis de governo aparece de maneira muito evidente como meio para atingir-se o desenvolvimento urbano defendido por especialistas e pelos países signatários. Uma vez consolidada a diretriz de descentralização administrativa e de valorização do papel das autoridades locais e regionais na promoção do desenvolvimento urbano, a conferência eleva a cooperação entre distintas instâncias de governo ao patamar de princípios, com os países signatários se comprometendo ainda a fomentar e efetivamente estabelecer as condições necessárias à efetiva coordenação entre entes nacionais e subnacionais. Isso se encontra muito evidente, por exemplo, nestes dispositivos da UN-Habitat (2017), previstos no documento final da conferência:

Principles and commitments:

15, (c), (i): Developing and implementing urban policies at the appropriate level, including in local-national and multi-stakeholder partnerships, building integrated systems of cities and human settlements and promoting cooperation among all levels of government to enable the achievement of sustainable integrated urban development. (...)

Call for action:

21. We urge all national, subnational and local governments, as well as all relevant stakeholders, in line with national policies and legislation, to revitalize, strengthen and create partnerships, enhancing coordination and cooperation to effectively implement the New Urban Agenda and realize our shared vision". 
47. We commit ourselves to taking appropriate steps to strengthen national, subnational and local institutions to support local economic development, fostering integration, cooperation, coordination and dialogue across levels of government and functional areas and relevant stakeholders. (...)

Effective implementation:

Building the urban governance structure: establishing a supportive framework 87. We will foster stronger coordination and cooperation among national, subnational and local governments, including through multilevel consultation mechanisms and by clearly defining the respective competences, tools and resources for each level of government.

90. We will, in line with countries' national legislation, support strengthening the capacity of subnational and local governments to implement effective local and metropolitan multilevel governance, across administrative borders, and based on functional territories, ensuring the involvement of subnational and local governments in decision-making and working to provide them with the necessary authority and resources to manage critical urban, metropolitan and territorial concerns. We will promote metropolitan governance that is inclusive and encompasses legal frameworks and reliable financing mechanisms, including sustainable debt management, as applicable. We will take measures to promote women's full and effective participation and equal rights in all fields and in leadership at all levels of decision-making, including in local governments.

Com efeito, a Habitat III ampliou a abordagem da conferência quanto às ações necessárias ao adequado enfrentamento dos problemas decorrentes da urbanização. Uma vez reformulada a tradicional organização do Estado, no sentido da superação de uma centralização administrativa que restringia a participação e o controle sociais, bem como a assunção de mais responsabilidades pelos demais entes subnacionais, as relações intergovernamentais passaram a ser objeto de tratamento condizente com a busca da eficácia das políticas de planejamento, organização e de gestão urbanoterritoriais.

\subsection{Especialistas nacionais}

Outro campo em que é possível perscrutar a disseminação do tema das relações interfederativas e governança urbano-territorial é entre especialistas que a trabalham direta ou indiretamente no Brasil. Para essa investigação, foram analisadas produções acadêmico-científicas que versaram sobre o referido objeto temático entre os anos de 2015 e de 2017, período marcado pelo advento do Estatuto da Metrópole. Como observado no início desta seção, as produções analisadas referem-se aos anais do ENANPUR e do EnANPAD realizados no referido período, assim como a artigos publicados pela Revista de Direito da Cidade e pela Revista Brasileira de Estudos Urbanos e Regionais (RBEUR), também entre 2015 e 2017. Entre a produção analisada, 39 trabalhos foram identificados por tratarem do tema das relações interfederativas e governança urbano-territorial, encontrando-se relacionados no Anexo. 
De pronto, constata-se a possibilidade de realizar análise comparativa entre os textos apresentados ou publicados em 2015, ano em que entrou em vigor o Estatuto da Metrópole, e os demais textos, os quais foram apresentados ou publicados em 2016 ou em 2017. O primeiro grupo de textos perfaz o total de 22 trabalhos, dos quais ao menos 3 correspondem às primeiras das produções acadêmico-científicas que foram apresentadas ou publicadas, versando sobre o Estatuto da Metrópole tal como a lei entrou em vigor, em 12 de janeiro de 2015. Da análise sobre a abordagem dos trabalhos do primeiro grupo de textos depreende-se que a disseminação do tema das relações interfederativas encontrava-se significativamente conectada à abordagem sobre arranjos institucionais em geral, com acentuado viés organizacional e com pouca abertura a aspectos associados a políticas setoriais ou a diferentes perspectivas dotadas de maior conteúdo sociológico.

É possível observar também que, nesse grupo de textos, ainda se nota a abordagem de aspectos basilares sobre a temática metropolitana, como a própria viabilidade de conceber-se o espaço metropolitano como unidade territorial para fins de planejamento ou mesmo a defesa de um marco legal para a adequada gestão de aglomerados urbanos marcados pela presença de interesses comuns entre diferentes entes de governo. Esse tipo de abordagem é capaz de evidenciar o estágio do tratamento normativo, institucional e político da própria questão relativa à governança metropolitana e à cooperação interfederativa à época, particularmente para aqueles trabalhos que foram elaborados antes do advento do Estatuto da Metrópole, que efetivamente consolidou marco comum a partir do qual se avançariam as questões metropolitanas, ao conferir maior sistematicidade conceitual e institucional a elas.

O segundo grupo de textos, isto é, o de produções apresentadas ou publicadas em 2016 ou em 2017, perfaz o total de 17 trabalhos, contrastando-se com os textos do primeiro grupo em razão de critério qualitativo, em face da maior variedade de abordagens sobre o tema referente à governança metropolitana e à cooperação interfederativa verificada nesse segundo grupo de textos. Isso fica evidente, por exemplo, ao analisarem-se seus enquadramentos temáticos, que versaram, dentre outros, sobre noções de urbanidade, identidade, território e política no planejamento urbano metropolitano; abordagens sobre o poder na cidade; coordenação interfederativa em políticas urbanas, particularmente saneamento básico e transportes; impactos do Programa de Aceleração do Crescimento (PAC); estudos urbano-regionais comparados; direito à água; ação coletiva e fronteiras da governança urbano-regional.

Assim sendo, pois, as produções apresentadas ou publicadas, após 2015, destacam-se por avançarem sobre questões bastante atuais, de que constituem exemplo as articulações em torno de políticas setoriais e as noções de identidade e de urbanidade metropolitanas, reforçando a sugestão de que, posteriormente ao Estatuto da Metrópole, muito da discussão relativa a aspectos político- 
institucionais, em que se enquadra a cooperação interfederativa, passaria naturalmente a ocorrer tendo como base a própria lei federal no 13.089/15, que tende a pacificar certas problematizações de base e a abrir espaço para discussões transversais e setoriais a respeito da temática sobre a governança metropolitana e as relações interfederativas.

Considerando as publicações em conjunto, não se constatou, quando fosse o caso, divergência significativa de pressupostos, como a necessidade de maior cooperação entre entes federados e de formalização de arranjos institucionais, mesmo para aqueles trabalhos elaborados anteriormente ao Estatuto da Metrópole. Por sua vez, no que se refere à origem da(as) instituição(ões) responsável(eis) pelas publicações, observou-se que a região Sudeste tem significativa proeminência na disseminação da temática em análise, estando relacionada a 24 dos 39 trabalhos, o que equivale a 61,53\% do total. As regiões Nordeste e Sul relacionam-se, cada uma, a 5 dos trabalhos analisados, ou 12,82\% do total, respectivamente. A região Norte tem relação com 2 dos trabalhos, ou 5,12\% do total, ao passo em que a região Centro-Oeste foi a única das regiões brasileiras a não se relacionar com os trabalhos identificados. Por seu turno, o Executivo federal, por meio do Instituto de Pesquisa Econômica Aplicada (IPEA), relacionou-se a 3 dos trabalhos identificados, equivalendo a 7,69\% do total, enquanto apenas 1 dos trabalhos, ou 2,56\% do total, decorre de pesquisa realizada em instituição no exterior. Este resultado sugere que as discussões sobre governança interfederativa é mais frequente onde existem mais aglomerados urbanos com grande peso demográfico, na região Sudeste, o que suscita maior preocupação em viabilizar os investimentos nas funções públicas de interesse comum.

\section{Avanços normativos na governança territorial metropolitana}

O processo de urbanização brasileira apresenta muitas semelhanças quanto ao fenômeno ocorrido em termos mundiais. Assim sendo, se na década de 1940 a população rural passou a migrar de forma mais intensa para a cidade, foi a partir dos anos 1970 que esse fluxo ganhou proporções realmente absolutas (MONTE-MÓR, 2005). O que se verificou a partir de então foi um intenso crescimento das cidades para além dos limites físico-jurídicos dos Municípios, impondo novos desafios de gestão urbana aos gestores públicos diante da crescente formação de aglomerados urbanos e de territórios metropolitanos.

Tal fato não passou despercebido pela Assembleia Constituinte de 1987/1988, prevendo o art. 25, § 3ำ, da Constituição Federal que os Estados podem, mediante lei complementar, instituir regiões metropolitanas, aglomerações urbanas e microrregiões para integrar a organização, o planejamento e a execução de funções públicas de interesse comum². 
Sob o prisma jurídico, a gestão dos aglomerados urbanos impõe uma redefinição do princípio federativo, ao passo em que diversos entes federativos se veem compelidos a atuar cooperativamente na consecução dos objetivos que importam a todos dentro de suas respectivas realidades. E se por um lado é necessária certa coordenação dos diversos atores institucionais, por outro, essa organização não pode ocorrer de maneira a suprimir a autonomia política, administrativa e financeira constitucionalmente garantida a todos os entes ${ }^{3}$.

Alguns avanços normativos se verificaram nessa tentativa de organização institucional. A Lei no 11.107/2005, por exemplo, dispôs sobre normas gerais para a União, os Estados, o Distrito Federal e os Municípios contratarem consórcios públicos para a realização de objetivos de interesse comum. Se de uma banda essa lei não foi suficiente para a resolução definitiva dos principais impasses de gestão metropolitana, de outra, certamente representou um progresso, em especial quanto à institucionalidade com que alguns temas passaram a ser tratados.

Visando a superar esse desafio é que o Estatuto da Metrópole, Lei ㄲo 13.089/2015, foi sancionado pela então Presidente da República Dilma Rousseff. Cuida-se de um marco normativo para o direito urbanístico e, especificamente para o que aqui interessa, para a relação interfederativa da governança metropolitana. É o que se extrai, por exemplo, da justificativa apresentada pelo então Deputado Federal Walter Feldman, autor do projeto de lei original sobre o Estatuto da Metrópole:

O Estatuto da Cidade teve a sabedoria de, ao construir o cenário do desenvolvimento municipal, integrar o urbano com o rural, o executivo com o orçamento e o operacional com a responsabilidade fiscal e com a probidade administrativa. [...] Neste quadro, soube ainda articular um amplo e inovador conjunto de instrumentos de planejamento, urbanísticos, tributários e financeiros, jurídicos e políticos, ambientais, institucionais e de gerenciamento, que situam a prática do desenvolvimento urbano brasileiro antes e depois do Estatuto das Cidade. Se o legislador, ao regulamentar os arts. 182 e 183 da Constituição Federal, foi pródigo nos acertos da normatização do desenvolvimento municipal, o mesmo não se deu quanto ao impacto das questões do desenvolvimento regional urbano nas suas diferentes escalas e possibilidades de ocorrência. Assim, é urgente que uma complementação, voltada para a regulamentação do universo das unidades regionais, de características essencialmente urbanas, dote o País de uma normatização que, de forma dinâmica e continuada, uniformize, articule e organize a ação dos entes federativos naqueles territórios em que funções de interesse comum tenham de ser necessariamente compartilhadas. ${ }^{4}$

A lei em questão começa por apresentar alguns conceitos básicos, porém passíveis de confusão, tais como aglomeração urbana, metrópole e região metropolitana e microrregiões. Em todos, há a ideia de que a cidade ultrapassa os limites territoriais do Município e, a partir de então, instaura-se o desafio interfederativo acima referido. Nesse ponto, foi salutar o veto presidencial aposto ao art. 1으, $\S 1$ o , inciso 
II, que previa a aplicação do Estatuto às cidades que, não obstante se situassem no território de apenas um Município, configurassem, em termos jurídicos, uma metrópole.

Além dessas definições supracitadas, a Lei no 13.089/2015 positiva, no art. 2o, o que se deve entender por função pública de interesse comum (inciso II), gestão plena (inciso III) e governança interfederativa (inciso IV). Mas, para o que aqui interessa, chama atenção a especificação, no inciso VI do mesmo artigo, do Plano de Desenvolvimento Urbano Integrado (PDUI), a saber: instrumento que estabelece, com base em processo permanente de planejamento, as diretrizes para o desenvolvimento urbano da região metropolitana ou da aglomeração urbana.

Tal como a Constituição Federal e o Estatuto da Cidade (Lei 10.257/2001) apontaram o plano diretor como o instrumento básico da política urbana municipal, o PDUI parece ter sido eleito também - apesar de não haver essa designação formal - o instrumento básico da política metropolitana. Sobre o PDUI, o art. 12 preceitua que:

Art. 12. O plano de desenvolvimento urbano integrado de região metropolitana ou de aglomeração urbana deverá considerar o conjunto de Municípios que compõem a unidade territorial urbana e abranger áreas urbanas e rurais.

$\S 1$ O O plano previsto no caput deste artigo deverá contemplar, no mínimo:

I - as diretrizes para as funções públicas de interesse comum, incluindo projetos estratégicos e ações prioritárias para investimentos;

II - o macrozoneamento da unidade territorial urbana;

III - as diretrizes quanto à articulação dos Municípios no parcelamento, uso e ocupação no solo urbano;

IV - as diretrizes quanto à articulação intersetorial das políticas públicas afetas à unidade territorial urbana;

$V$ - a delimitação das áreas com restrições à urbanização visando à proteção do patrimônio ambiental ou cultural, bem como das áreas sujeitas a controle especial pelo risco de desastres naturais, se existirem; (Redação dada pela Lei no 13.683, de 2018)

VI - o sistema de acompanhamento e controle de suas disposições; e (Redação dada pela Lei no 13.683, de 2018)

VII - as diretrizes mínimas para implementação de efetiva política pública de regularização fundiária urbana, nos termos da Lei no 13.465, de 11 de julho de 2017. (Incluído pela Lei no 13.683, de 2018)

$\S 2$ o No processo de elaboração do plano previsto no caput deste artigo e na fiscalização de sua aplicação, serão assegurados:

I - a promoção de audiências públicas e debates com a participação de representantes da sociedade civil e da população, em todos os Municípios integrantes da unidade territorial urbana;

II - a publicidade quanto aos documentos e informações produzidos; e

III - o acompanhamento pelo Ministério Público.

$\S 3$ ㅇ As audiências públicas a que se refere o inciso I do $\S 2$ 을 deste artigo serão precedidas de ampla divulgação em todos os Municípios integrantes da unidade territorial urbana. (Incluído pela Lei no 13.683, de 2018)

$\S$ 4ㅇ A realização de audiências públicas ocorrerá segundo os critérios estabelecidos pela instância colegiada deliberativa a que se refere o art. 8 desta Lei, respeitadas as disposições desta Lei e das leis complementares que instituírem as unidades territoriais. (Incluído pela Lei no 13.683, de 2018) 
Em suma, o PDUI é o instrumento pelo qual a gestão cooperativa da região metropolitana restará viabilizada sem a supressão da autonomia federativa dos entes envolvidos. É na elaboração (e revisão) dele que os diálogos institucionais se iniciam (e continuam) materialmente, assim como se consolidam como diretrizes normativas a serem seguidas na gestão do território.

No plano devem constar todas as especificidades que o legislador federal ordinário não poderia nem deveria prever, ante a heterogeneidade das regiões metropolitanas já existentes ou mesmo ainda não criadas. Daí também a necessidade de participação interinstitucional e popular na sua confecção, pois é a partir dele que as políticas públicas devem ser gestadas e executadas.

Tamanha a importância do PDUI que - tal como o Plano Diretor no Estatuto da Cidade ${ }^{5}$ - ele foi inicialmente o único instrumento de instituição e utilização compulsórias, havendo na edição original da lei até mesmo previsão de que eventual omissão do Governador ou agente público importaria em sua responsabilização por improbidade administrativa (art. 21). Cuidava-se de infração formal que se instauraria independentemente da existência ou não de prejuízo para a governança.

Conforme se demonstrará abaixo, motivos dos mais diversos levaram a que o prazo inicial conferido pelo legislador - três anos da publicação da lei, para as regiões metropolitanas já instituídas - não fosse observado por quase todos os gestores. Por essa razão, o Deputado Federal Miguel Haddad (PSDB/SP) propôs em 07/11/2017 o projeto de lei no 9.011/2017 visando a prorrogar esse limite, com a seguinte justificativa:

Outro aspecto relevante diz respeito ao fato de que até o presente não há PDUI elaborado de acordo com os requisitos exigidos pelo Estatuto da Metrópole, sendo apenas sete Regiões Metropolitanas, das vinte mais importantes do país, que avançaram além dos Termos de Referência para a sua elaboração. Por fim, em vista da grave consequência de improbidade administrativa, nos termos da Lei no 8.429, de 2 de junho de 1992, a ser imputada a governadores e agentes públicos, na hipótese de não execução do PDUI no prazo legal, sua dilação é imprescindível.

Mesmo com requerimento de urgência urgentíssima formulado pelos líderes das principais bancadas da situação e oposição, o PL não tramitou de forma célere. Nesse contexto e ante a exiguidade do tempo, o Presidente Michel Temer editou a Medida Provisória no 818/2018 com texto muito similar ao do projeto de lei, estendendo o prazo do art. 21, inciso I, alínea "b" até 31 de dezembro de 2021.

Com a conversão dessa MP na Lei no 13.683/2018, a previsão de prazo para elaboração do PDUI restou revogada, bem como a sanção específica de improbidade administrativa para os Governadores e agentes públicos que se quedassem inertes. Por outro lado, a ausência de prazo e peculiar punição não legitima eventual omissão dos responsáveis, que continuam tendo obrigação de elaborar o PDUI, 
na hipótese de o colegiado da microrregião decidir sobre a adoção do Plano de Desenvolvimento Urbano ou quaisquer matérias de impacto, conforme dispõe a redação do parágrafo único incluído pela Lei no 13.683/2018.

Feita essa breve análise, cumpre verificar a situação das principais regiões metropolitanas brasileiras, mais precisamente daquelas que abrangem as capitais estaduais das cinco regiões políticas nacionais.

5. Pesquisa de campo: avanços na elaboração dos planos diretores urbanos integrados e criação de agências metropolitanas

O presente relatório, baseado no Anexo 2, apresenta resultados de um estudo que analisou a implementação do Plano de Desenvolvimento Urbano Integrado (PDUI) por parte das regiões metropolitanas que têm como núcleo capitais estaduais. A pesquisa teve como escopo selecionar a região metropolitana consolidada no entorno de capitais de Estados da Federação, bem como observar o andamento da elaboração do PDUI pelas respectivas autoridades metropolitanas. A partir desse recorte, foi possível obter uma visão holística da forma como a obrigatoriedade estabelecida pelo art. 10 da Lei no 13.089/2015, que instituiu o Estatuto da Metrópole, vem sendo assumida por esses entes federativos.

Tendo-se em vista os efeitos da Lei no 13.683/2018, que, como visto, revogou os prazos para a elaboração de PDUI, bem como a sanção prevista para agentes públicos que não cumprissem a obrigação de elaboração e de aprovação dos referidos Planos, é possível afirmar que, até a data da elaboração deste relatório, nenhuma das regiões metropolitanas pesquisadas encontrava-se em mora com relação à elaboração, aprovação e implementação do referido plano.

Há também de ser reiterado que a Medida Provisória no 818/2018 já havia retirado a necessidade de se aprovar o PDUI por lei complementar, exigindo-se tão somente a sua aprovação pela instância colegiada deliberativa, a que se denomina autoridade metropolitana. Isso sugere que, quando da redação da referida MP, atentou-se para o fato de que não há no ordenamento pátrio a possibilidade de o executivo federal obrigar o legislativo estadual a aprovar uma lei em prazo pré-estabelecido, sob pena de se afrontarem os arts. $2^{0^{6}}$ e $18^{7}$ da Constituição Federal.

O presente estudo teve como propósito utilizar as regiões metropolitanas estabelecidas nas capitais dos 26 Estados brasileiros e do Distrito Federal-DF. No entanto, considerando o fato de que os Estados do Acre e do Mato Grosso do Sul não dispõem de regiões metropolitanas, partiu-se de uma base que contém 24 capitais estaduais, além do DF. 
Cabe salientar que, como uma região metropolitana é composta por municípios ${ }^{8}$ e o DF não pode se dividir nesses entes políticos ${ }^{9}$, não se exigiu, inicialmente, a elaboração de PDUI para a sua Região Integrada de Desenvolvimento Econômico - RIDE, já que o Plano somente era obrigatório para aglomerações urbanas e regiões metropolitanas, conforme se depreende da razão de veto do art. 19 do Estatuto da Metrópole ${ }^{10}$.

Em que pese a não obrigatoriedade do plano para a RIDE, há de se destacar que a Região Integrada de Desenvolvimento da Grande Teresina está com o seu plano em fase de elaboração. Ressalte-se que atualmente a RIDE Teresina encontra-se regulada por um Plano Executivo denominado Programa de Desenvolvimento Urbano Integrado - Teresina Sustentável. Outrossim, para financiamento desse programa, foi solicitado o aporte de US\$ 45 milhões ao Banco de Desenvolvimento da América Latina (CAF). ${ }^{11}$

Encontram-se em fase de elaboração mais avançada os planos de Boa Vista, Cuiabá, Curitiba, Recife, Rio de Janeiro, Salvador e São Luís. No que se refere a Cuiabá, foi encaminhado à Assembleia Legislativa o Projeto de Lei Complementar no 07/2018, criando o PDDI/RMVRC - Plano Diretor de Desenvolvimento Integrado da Região Metropolitana do Vale do Rio Cuiabá, proposta também denominada de Plano Metropolitano, enquanto que, em São Luís, todo o processo de elaboração do que a autoridade metropolitana resolveu chamar de PDDI - Plano Diretor de Desenvolvimento Integrado da Região Metropolitana da Grande São Luís conta com uma plataforma digital que lista todas as etapas a serem cumpridas para a elaboração do Plano, que envolvem pesquisa de campo, oficinas comunitárias e audiências públicas. Tal iniciativa oferece a oportunidade de o cidadão poder ter acesso às fases de elaboração do Plano, de forma simples e rápida ${ }^{12}$.

Com relação à Região Metropolitana do Rio de Janeiro, o governo estadual, por meio da Câmara Metropolitana, apresentou em junho de 2018 o Plano Estratégico de Desenvolvimento Urbano Integrado (PEDUI), denominação local do PDUI, contendo um conjunto de 131 ações para o planejamento da região metropolitana do RJ pelos próximos 25 anos $^{13}$; não obstante, o PEDUI ainda precisa ser aprovado pela instância legislativa do Estado.

Diferentemente, encontram-se em estágio de elaboração menos avançado as regiões metropolitanas de Fortaleza, Goiânia, Porto Alegre e Natal. Desta última há apenas um Plano de Desenvolvimento Sustentável da Região Metropolitana de Natal - Natal Metrópole 2020, feito em 2007.

Já São Paulo atingiu uma fase de elaboração bem mais adiantada, pois, tal qual São Luís, criou uma plataforma digital que dispõe de cronograma que contém cada uma das fases de execução do PDUI, além de informações sobre seu estágio atual. O site na internet permite maior acessibilidade aos munícipes, além de trazer informações sobre as audiências públicas de mobilização, oficinas subregionais e incorporação da sociedade civil na Comissão Técnica e no Comitê Executivo ${ }^{14}$. 
As regiões metropolitanas de Belém, Florianópolis, João Pessoa, Macapá, Maceió, Manaus e Porto Velho sequer iniciaram os trabalhos para elaboração do plano. Já em relação às capitais de Aracajú e Palmas, vê-se uma tentativa de dar início à sua elaboração. No que se refere a Aracaju, há notícias de que o Procurador Geral do Estado Sergipe Pedro Dias apresentou na Câmara Municipal um Projeto de Lei Complementar ${ }^{15}$, ao qual não se teve acesso pela internet, enquanto em Palmas há somente um Projeto de Desenvolvimento Regional Integrado e Sustentável (PDRIS) ligado à Secretaria de Meio Ambiente ${ }^{16}$.

A Região Metropolitana de Belo Horizonte - RMBH conta com um Projeto de Lei Complementar aprovado pelo Conselho Deliberativo da RMBH, sua autoridade metropolitana, em 2011. Tal projeto foi encaminhado para o legislativo estadual em 2017, ganhando o número de Projeto de Lei Complementar (PLC) 74/17 17 . Tal PLC foi encaminhado à Assembleia dentro do prazo limite original do Estatuto, isto é, aquele anterior à mudança promovida pela MP no 818/18.

A única região metropolitana localizada em capital de Estado que logrou elaborar e aprovar o seu PDUI dentro do prazo original de 3 (três) anos estabelecido pelo Estatuto, que findaria em 2018, foi a de Vitória. O plano contou com o trabalho do Conselho Metropolitano de Desenvolvimento da Grande Vitória (COMDEVIT), sua autoridade metropolitana. O plano foi aprovado em 2017 por meio da Lei Complementar do Estado do Espírito Santo № $872^{18}$.

Na maioria das capitais pesquisadas, não foi encontrada indicação expressa da autoridade metropolitana, mas de órgãos ou entidades diversas com a atribuição de coordenar as ações pertinentes à elaboração e à aprovação do PDUI, com predominância da atuação de secretarias estaduais ou municipais.

A atuação direta das secretarias de estado foi verificada em Aracaju, Belém, Boa Vista, Fortaleza, João Pessoa, Macapá, Maceió, Palmas e Porto Velho, enquanto que, na Região Metropolitana de Desenvolvimento da Grande Teresina, a execução prevista até então ocorrerá por meio da Secretaria Municipal de Planejamento. Para as regiões metropolitanas de Cuiabá, Curitiba, Florianópolis, Recife e Salvador, a atribuição será desempenhada por autarquias; por sua vez, para as regiões metropolitanas de Goiânia, Natal e Vitória, foi prevista a atuação de fundações estaduais. Quanto à região metropolitana do Rio de Janeiro, verificou-se a presença de um órgão interinstitucional, ao passo que, em São Paulo e São Luís, atribuiu-se tal execução a instituições públicas estaduais.

No que diz respeito ao Fundo de Desenvolvimento Metropolitano, verificou-se haver proposta para a sua criação nas regiões metropolitanas de Cuiabá, Curitiba, Florianópolis, Fortaleza, Porto Alegre, Recife, Rio de Janeiro, São Paulo e Vitória. 


\section{Considerações finais}

O tema relativo à cooperação interfederativa para a governança metropolitana tem ganhado crescente importância no âmbito das discussões urbano-territoriais e políticas, como demonstra a disseminação dessa temática entre especialistas. Consolidando-se como diretriz e compromisso de governos na ONU-Habitat, a cooperação entre distintas entidades de governo para a gestão de regiões metropolitanas não escapou aos estudos de especialistas nacionais, que têm adotado abordagens cada vez mais diversas para esse campo, após a maior sistematicidade institucional conferida pelo Estatuto da Metrópole. Não obstante, a análise realizada sobre a disseminação desse tema, no Brasil, sugere que a concentração das produções acadêmico-científicas em instituições da região Sudeste pode afetar a efetiva compreensão da realidade metropolitana em termos nacionais, particularmente em um país dotado de extensas dimensões e diversidades socioculturais, econômicas e políticas.

No que se refere aos avanços normativos na governança territorial metropolitana, contatou-se que, de todas as regiões metropolitanas que integraram o recorte deste trabalho, apenas a da Grande Vitória logrou aprovar o PDUI dentro do prazo fixado originalmente pelo Estatuto da Metrópole. E, mesmo nesse caso, houve necessidade de relegar para outra lei estadual a tarefa de disciplinar detalhadamente a estrutura da governança interfederativa.

Diversas causas relacionam-se a esse diagnóstico. A negligência de agentes públicos responsáveis é certamente uma delas, tal como se observou na RM de Manaus, que, desde 2015, não avançou em nenhum dos aspectos analisados. Não obstante, essa realidade não se repete em todas as demais. Pelo contrário, verificou-se que muitas regiões metropolitanas têm envidado esforços no sentido de formular um plano de governança interfederativa não apenas formal, mas materialmente relevante, produzido de maneira tecnicamente fundamentada, com participação popular. Apesar disso, mesmo nesses casos, a existência de um PDUI formalizado em lei complementar estadual ainda não é uma realidade.

Ante essas circunstâncias, é provável que o prazo de três anos inicialmente estabelecido para o aperfeiçoamento institucional de regiões metropolitanas já instituídas não tenha sido suficiente para a confecção e para a aprovação de um PDUI substantivo, é dizer, de um plano que efetivamente seja capaz de orientar a gestão interfederativa das cidades. Afinal, as etapas a serem percorridas são muitas e são complexas, demandando tempo de maturação, mesmo diante de uma Administração Pública eficiente. De fato, a instituição de uma agência metropolitana é o primeiro desafio enfrentado pela governança territorial, notadamente quanto à necessidade de cooperação entre entes federativos que, embora gozem de mesma hierarquia jurídica, sem qualquer grau de subordinação entre si, são bastante assimétricos em suas capacidades técnicas, financeiras, políticas, bem como em suas dimensões 
demográficas e territoriais. A viabilização de participação social também demanda tempo e adequado arcabouço institucional, com realização de audiências públicas plurais que viabilizem a colaboração de distintos setores sociais.

De toda sorte, a remessa do PDUI como projeto de lei a ser analisado pelas Assembleias Legislativas não é garantia de sua aprovação, seja por discordância dos Parlamentares representantes do povo ou pela priorização de outras pautas legislativas. Nesse ponto, a prorrogação por novos dois anos implementada pela Medida Provisória no 818/2018 foi salutar no sentido de se evitar uma indevida responsabilização das autoridades que, apesar de reais esforços, não conseguiriam percorrer todo o processo de elaboração e de aprovação do plano metropolitano. De outro lado, a revogação do Art. 21 do Estatuto da Metrópole pela Lei de conversão no 13.683/2018 caracteriza um retrocesso normativo a ser lamentado, uma vez que suscita maior atraso nos esforços de coordenação interfederativa. ${ }^{19}$ Anexos: 


\section{PLANILHA DOS ESPECIALISTAS}

\begin{tabular}{|c|c|c|c|c|}
\hline Nome do estudo & $\begin{array}{c}\text { Ano do } \\
\text { estudo/fonte }\end{array}$ & $\begin{array}{l}\text { Quem realizou o } \\
\text { estudo? }\end{array}$ & $\begin{array}{l}\text { Local onde se } \\
\text { localiza o } \\
\text { objeto de } \\
\text { estudo }\end{array}$ & Análise setorial? \\
\hline $\begin{array}{c}\text { ESTRATÉGIAS DE GOVERNANÇA TERRITORIAL NO ESTADO DE } \\
\text { SÃO PAULO: AMBIENTE INSTITUCIONAL E PERSPECTIVAS DE } \\
\text { COESÃO }\end{array}$ & 2015/ENANPUR & $\begin{array}{c}\text { Universidades - } \\
\text { UNESP e UFABC }\end{array}$ & São Paulo & $\begin{array}{c}\text { Planejamento e } \\
\text { desenvolvimento territorial }\end{array}$ \\
\hline $\begin{array}{l}\text { A IMPORTÂNCIA DO PLANEJAMENTO E DA BOA GOVERNANÇA } \\
\text { PARA A PROMOÇÃO DO DESENVOLVIMENTO REGIONAL DO } \\
\text { ESTADO DO PARÁ: A QUESTÃO DA DIVISÃO TERRITORIAL }\end{array}$ & 2015/ENANPUR & $\begin{array}{l}\text { Universidade } \\
\text { UFOPA }\end{array}$ & Pará & $\begin{array}{c}\text { Planejamento e } \\
\text { desenvolvimento regional }\end{array}$ \\
\hline $\begin{array}{c}\text { POLÍTICAS DE DESENVOLVIMENTO, TERRITÓRIO E PACTO } \\
\text { FEDERATIVO: AVANÇOS E LIMITAÇÕES NO QUADRO ATUAL } \\
(2000 / 2012)\end{array}$ & 2015/ENANPUR & IPEA & Nacional & $\begin{array}{r}\text { Problematização das politicas } \\
\text { de desenvolvimento regional }\end{array}$ \\
\hline \begin{tabular}{|c|} 
A INGOVERNABILIDADE METROPOLITANA EMBORA A MAIORIA \\
DA POPULAÇÃO BRASILEIRA JÁ RESIDA EM REGIÕES \\
METROPOLITANAS, NÃO EXISTE AINDA NO ORDENAMENTO \\
JURÍDICO BRASILEIRO UM MARCO LEGAL APROPRIADO À GESTÃO \\
DESTES TERRITÓRIOS \\
\end{tabular} & 2015/ENANPUR & $\begin{array}{c}\text { Prefeitura da Cidade } \\
\text { do Rio de Janeiro }\end{array}$ & Nacional & $\begin{array}{c}\text { Problematização acerca dos } \\
\text { limites da autonomia local em } \\
\text { áreas conurbadas }\end{array}$ \\
\hline $\begin{array}{c}\text { COOPERAÇÕES TERRITORIAIS DE ÂMBITO URBANO-REGIONAL: } \\
\text { SEMELHANÇAS E DIFERENÇAS NAS COOPERAÇÕES } \\
\text { INTERMUNICIPAIS NO BRASIL E NA FRANÇA } \\
\end{array}$ & 2015/ENANPUR & $\begin{array}{l}\text { Universidades - } \\
\text { IMED e UFRJ }\end{array}$ & $\begin{array}{l}\text { Brasil X } \\
\text { França }\end{array}$ & $\begin{array}{c}\text { Cooperações territoriais } \\
\text { pluriescalares }\end{array}$ \\
\hline $\begin{array}{l}\text { UM BALANÇO CRÍTICO DA EXPERIÊNCIA DE PLANEJAMENTO } \\
\text { URBANO NA GRANDE CURITIBA NA ÚLTIMA DÉCADA (2004-2014) }\end{array}$ & 2015/ENANPUR & USP & Curitiba- PR & $\begin{array}{c}\text { Distinções entre o } \\
\text { planejamento e gestão } \\
\text { territorial da Região } \\
\text { Metropolitana de Curitiba e } \\
\text { do país }\end{array}$ \\
\hline $\begin{array}{c}\text { INSTITUCIONALIDADES DO PLANEJAMENTO E GESTÃO } \\
\text { TERRITORIAL: DESAFIOS DA GOVERNANÇA DEMOCRÁTICA NUMA } \\
\text { PERSPECTIVA INTERESCALAR }\end{array}$ & 2015/ENANPUR & \begin{tabular}{|l|} 
Universidades - \\
UFRGS e UNISC
\end{tabular} & Nacional & $\begin{array}{c}\begin{array}{c}\text { Desafios das municipalidades } \\
\text { para coma a governança } \\
\text { regional }\end{array} \\
\end{array}$ \\
\hline $\begin{array}{c}\text { OS AGLOMERADOS URBANOS DA REGIÃO LESTE SUDESTE DA } \\
\text { ZONA PERIMETROPOLITANA DE BELO HORIZONTE (dúvida, vamos ter } \\
\text { que ler o artigo inteiro) }\end{array}$ & 2015/ENANPUR & UFMG & $\begin{array}{c}\text { Belo Horizonte- } \\
\text { MG }\end{array}$ & \begin{tabular}{|c|} 
Aglomerados urbanos da \\
região leste sudeste dentro da \\
zona perimetropolitana de \\
Belo Horizonte
\end{tabular} \\
\hline $\begin{array}{l}\text { A REGIÃO METROPOLITANA DO RIO DE JANEIRO COMO ÁREA } \\
\text { INTEGRADA E REGIÃO DE GOVERNO }\end{array}$ & 2015/ENANPUR & USP & Rio de Janeiro & $\begin{array}{l}\text { Conceituação de região } \\
\text { metropolitana }\end{array}$ \\
\hline $\begin{array}{c}\text { ARRANJOS INSTITUCIONAIS NO BRASIL - PARADOXOS DE } \\
\text { RIQUEZA E DÉFICIT SOCIAL: O ESTUDO DA DIMENSÃO } \\
\text { TERRITORIAL PARA O PLANEJAMENTO E A MACROMETRÓPOLE } \\
\text { PAULISTA }\end{array}$ & 2015/ENANPUR & UNIVAP & São Paulo & $\begin{array}{l}\text { Dimensão territorial e } \\
\text { escalada ao nível de } \\
\text { macrometrópole }\end{array}$ \\
\hline $\begin{array}{c}\text { O BRASIL METROPOLITANO: ESCALA REAL, ENTE INEXISTENTE E } \\
\text { AS TENSÕES DA GESTÃO E DA GOVERNANÇA METROPOLITANAS } \\
\text { NO PAÍS }\end{array}$ & 2015/ENANPUR & IPEA & Nacional & $\begin{array}{l}\text { Análise institucional dos } \\
\text { arranjos governativos }\end{array}$ \\
\hline $\begin{array}{l}\text { ENTRE PLANOS E INSTITUIÇÕES: A EMERGÊNCIA E CIRCULAÇÃO } \\
\text { DO CONCEITO DE REGIÃO METROPOLITANA COMO UNIDADE DE } \\
\text { PLANEJAMENTO }\end{array}$ & 2015/ENANPUR & USP & $\begin{array}{c}\text { EUA X Eropa } \\
\text { X Brasil }\end{array}$ & $\begin{array}{l}\text { Apresentação de planos e } \\
\text { instituições metropolitanas }\end{array}$ \\
\hline $\begin{array}{c}\text { O PLANEJAMENTO PARA O DESENVOLVIMENTO E O PAPEL DO } \\
\text { CONSÓRCIO PÚBLICO INTERMUNICIPAL DO TAPAJÓS NA } \\
\text { AMAZÔNIA: ENSAIOS SOBRE O DESENVOLVIMENTO DO } \\
\text { TERRITÓRIO }\end{array}$ & 2015/ENANPUR & UFOPA & Tapajós- PA & $\begin{array}{l}\text { Consórcio Intermunicipal e } \\
\text { desenvolvimento territorial } \\
\text { sustentável }\end{array}$ \\
\hline $\begin{array}{l}\text { COOPERAÇÃO ENTRE MUNICÍPIOS: UMA ANÁLISE } \\
\text { INSTITUCIONAL }\end{array}$ & 2015/ENANPUR & UFJF & Nacional & $\begin{array}{l}\text { Problematização acerca de } \\
\text { consórcios públicos }\end{array}$ \\
\hline $\begin{array}{l}\text { Uma Década do Marco Institucional-Legal do Modelo de Gestão } \\
\text { Descentralizada para o Desenvolvimento de Santa Catarina: Estratégia de um } \\
\text { Governo ou Governança como Estratégia? }\end{array}$ & 2015/ENANPAD & $\begin{array}{c}\text { Fundação Escola de } \\
\text { Governo ENA }\end{array}$ & Santa Catarina & $\begin{array}{l}\text { Migração da estrutura de } \\
\text { governo para governança } \\
\text { pública }\end{array}$ \\
\hline Governança Metropolitana no Grande ABC: Iniciativas Isoladas & 2015/ENANPAD & \begin{tabular}{|c|} 
Universidades - \\
Centro Universitário \\
FEI e USCS \\
\end{tabular} & $\begin{array}{c}\text { ABC Paulista- } \\
\text { SP }\end{array}$ & $\begin{array}{l}\text { Competição VS Integração } \\
\text { entre as cidades }\end{array}$ \\
\hline Governança Metropolitana: uma Alternativa aos Problemas Regionais & 2016/ENANPAD & $\begin{array}{c}\text { Centro Universitário } \\
\text { FEI }\end{array}$ & Nacional & $\begin{array}{c}\text { Aprimoramento de políticas } \\
\text { públicas }\end{array}$ \\
\hline $\begin{array}{c}\text { Os Consórcios Públicos como Estratégia de Gestão Territorial do Federalismo } \\
\text { Brasileiro: o Caso do Consórcio Portal do Sertão - BA }\end{array}$ & 2016/ENANPAD & UFBA & Bahia & $\begin{array}{l}\text { Cooperação territorial os } \\
\text { consórcios públicos }\end{array}$ \\
\hline $\begin{array}{c}\text { Governança e politicas públicas: um estudo exploratório sobre o PAC e seus } \\
\text { desafios na implementação sob a ótica municipal. }\end{array}$ & 2017/ENANPAD & USP & São Paulo & $\begin{array}{c}\text { Problemática acerca da } \\
\text { articulação intergovernamental }\end{array}$ \\
\hline
\end{tabular}




\begin{tabular}{|c|c|c|c|c|}
\hline $\begin{array}{l}\text { A caracterização das regiões metropolitanas e aglomerações urbanas pelo IBGE: } \\
\text { Limites e avanços do Estatuto da Metrópole }\end{array}$ & 2017/ENANPUR & \begin{tabular}{|c|} 
Universidade \\
Federal do $\mathrm{ABC}-$ \\
$\mathrm{UFABC}$ \\
\end{tabular} & Nacional & $\begin{array}{l}\text { Estado, Planejamento e } \\
\text { Gestão de Território }\end{array}$ \\
\hline $\begin{array}{l}\text { Relações intergovernamentais e trajetórias dependentes na implementação da Lei } \\
\text { Nacional de Saneamento Bá+22:31sico na Região Metropolitana de São Paulo }\end{array}$ & 2017/ENANPUR & UFABC & São Paulo & \begin{tabular}{|c|}
$\begin{array}{c}\text { Estado, Planejamento e Gestão } \\
\text { do Território (Politica de } \\
\text { Saneamento }\end{array}$ \\
\end{tabular} \\
\hline $\begin{array}{l}\text { Território usado e dinâmicas de partilha do poder: politica e transporte público } \\
\text { metropolitano em São Paulo }\end{array}$ & 2017/ENANPUR & Unesp-Rio Claro & São Paulo & $\begin{array}{c}\text { governança interfederativa; } \\
\text { gestão compartilhada; gestão } \\
\text { metropolitana; Estatuto das } \\
\text { Metrópoles. } \\
\end{array}$ \\
\hline $\begin{array}{l}\text { Qual governança metropolitana? Embate entre as agendas competitiva e } \\
\text { cooperativa nos rumos de duas metrópoles contemporâneas: Belo Horizonte e Lille } \\
\text { (França) }\end{array}$ & 2017/ENANPUR & $\begin{array}{c}\text { Universidade } \\
\text { Católica de Minas } \\
\text { Gerais - PUC Minas }\end{array}$ & $\begin{array}{l}\text { MG (Brasil) e } \\
\text { Área } \\
\text { Metropolitana } \\
\text { de Lille } \\
\text { (França) } \\
\end{array}$ & $\begin{array}{l}\text { Planejamento e Estruturação } \\
\text { Metropolitana e Regional }\end{array}$ \\
\hline $\begin{array}{l}\text { Experiências de gestão e governança metropolitanas pós-constituição federal de } \\
\qquad 1988\end{array}$ & 2017/ENANPUR & $\begin{array}{c}\text { Consórcio Quanta } \\
\text { Lerner }\end{array}$ & $\begin{array}{l}\text { MG, SP e } \\
\text { Bahia }\end{array}$ & \begin{tabular}{|c|}
$\begin{array}{c}\text { produção e gestão do espaço } \\
\text { urbano, metropolitano e } \\
\text { regional }\end{array}$ \\
\end{tabular} \\
\hline $\begin{array}{l}\text { Direito à água: conflitos e disputas na Região do Leste Metropolitano do Rio de } \\
\text { Janeiro }\end{array}$ & 2017/ENANPUR & PPGAU/UFF & RJ & Conflitos socioambientais \\
\hline $\begin{array}{c}\text { As 'fronteiras' da governança urbano-regional: reflexões sobre proximidades, ação } \\
\text { coletiva e aprendizagem }\end{array}$ & 2017/ENANPUR & \begin{tabular}{|c|}
$\begin{array}{c}\text { Universidade Federal } \\
\text { do Paraná }\end{array}$ \\
\end{tabular} & Nacional & $\begin{array}{l}\text { Politicas Territoriais: entre } \\
\text { Redes, Fronteiras e Escalas } \\
\end{array}$ \\
\hline $\begin{array}{l}\text { Território, identidade e politica: reflexões sobre os lugares de urbanidade } \\
\text { metropolitana no contexto do planejamento urbano na RMBH }\end{array}$ & 2017/ENANPUR & NPGAU-UFMG & MG & $\begin{array}{l}\text { Politicas Territoriais: entre } \\
\text { Redes, Fronteiras e Escalas } \\
\end{array}$ \\
\hline Regimes urbanos e governança democrática: abordagens sobre o poder na cidade & 2017/ENANPUR & UFRN & Nacional & $\begin{array}{c}\text { Regimes urbanos e governança } \\
\text { colaborativa }\end{array}$ \\
\hline $\begin{array}{l}\text { Potencializando o êxito das politicas públicas: a integração de municíios por meio } \\
\text { da troca de conhecimentos }\end{array}$ & 2017/ENANPUR & UTFPR & Paraná & Paraná \\
\hline $\begin{array}{c}\text { O Estatuto da Metrópole e novas esperanças para o futuro da politica de } \\
\text { planificação e planejamento no Brasil: O plano de desenvolvimento urbano integrado }\end{array}$ & $\begin{array}{c}\text { 2015/Revista } \\
\text { Direito da Cidade }\end{array}$ & UERJ & Nacional & $\begin{array}{l}\text { planificação e planejamento } \\
\text { urbanos }\end{array}$ \\
\hline $\begin{array}{l}\text { Politica urbana no contexto federativo brasileiro: um Avanço normativo na gestão } \\
\qquad \text { dos aglomerados urbanos }\end{array}$ & $\begin{array}{c}\text { 2015/Revista } \\
\text { Direito da Cidade }\end{array}$ & USP/UERJ & Nacional & política urbana \\
\hline $\begin{array}{l}\text { Regiões metropolitanas e funções públicas de interesse comum: } \mathrm{O} \text { ordenamento } \\
\text { territorial diante do Estatuto da Metropole }\end{array}$ & $\left|\begin{array}{c}\text { 2015/Revista } \\
\text { Direito da Cidade }\end{array}\right|$ & UERJ/PUC-Rio & Nacional & Ordenamento territorial \\
\hline $\begin{array}{l}\text { A Gestão territorial das Regiões Metropolitanas no alcance do desenvolvimento } \\
\text { urbano e na redução das disparidades regionais no Brasil }\end{array}$ & $\left|\begin{array}{c}\text { 2015/Revista } \\
\text { Direito da Cidade }\end{array}\right|$ & \begin{tabular}{|c|}
$\begin{array}{c}\text { Universidade Federal } \\
\text { do Rio Grande do } \\
\text { Norte }\end{array}$ \\
\end{tabular} & Nacional & Gestão territorial metropolitana \\
\hline $\begin{array}{c}\text { A governação de territórios metropolitanos . contexto institucional e de planeamento } \\
\text { nas regiões de Madrid, Barcelona, Paris e Lisboa }\end{array}$ & $\left|\begin{array}{c}\text { 2015/Revista } \\
\text { Direito da Cidade }\end{array}\right|$ & $\begin{array}{c}\text { Universidad } \\
\text { Politécnica de } \\
\text { Madrid, España e } \\
\text { Universidade de } \\
\text { Lisboa, Portugal. } \\
\end{array}$ & $\begin{array}{l}\text { Cidades } \\
\text { europeias }\end{array}$ & $\begin{array}{l}\text { Governança territorial } \\
\text { metropolitana }\end{array}$ \\
\hline $\begin{array}{l}\text { SL } 25 \text { - Superando o Impasse Metropolitano? A Adequação das Regiões } \\
\text { Metropolitanas ao Estatuto da Metrópole Coord. Marco Aurélio Costa }\end{array}$ & $\begin{array}{l}\text { 2017/ XVII } \\
\text { ENANPUR } \\
\end{array}$ & IPEA (coord.) & $\mathrm{RJ}$ e BA & Gestão territorial metropolitana \\
\hline SL 26 - Estratégias de Coordenação Interfederativa em Políticas Urbanas & $\begin{array}{r}2017 / \text { XVII } \\
\text { ENANPUR } \\
\end{array}$ & $\begin{array}{l}\text { UERJ e UFRJ } \\
\text { (coord.) }\end{array}$ & RJ & Gestão territorial metropolitana \\
\hline $\begin{array}{l}\text { SL } 30 \text { - Narrativas das práxis do planejamento urbano e regional como guia ao } \\
\text { enfrentamento da crise: o lugar das águas Coord. Fabiano Rocha Diniz }\end{array}$ & $\begin{array}{l}\text { 2017/ XVII } \\
\text { ENANPUR } \\
\end{array}$ & UFPE (coord.) & MG e PE & Gestão territorial metropolitana \\
\hline $\begin{array}{l}\text { 1) Sistema politico multinivel no Brasil: uma análise da relação entre transferências } \\
\text { intergovernamentais e redução das desigualdades territoriais no Estado do Paraná | } \\
\text { Carin Caroline Deda, Samira Kauchakje | RBEUR, v. 19, n. } 3 \text { (2017) }\end{array}$ & \begin{tabular}{c|}
$2017 /$ II- \\
REVISTA \\
BRASILEIRA \\
DE ESTUDOS \\
URBANOS E \\
REGIONAIS \\
\end{tabular} & *-*** & PR & Gestão territorial metropolitana \\
\hline 2) Metropolitan ungovernability | Rose Compans | RBEUR, v. 17, n. 2 (2015) & \begin{tabular}{c|}
$2015 /$ II- \\
REVISTA \\
BRASILEIRA \\
DE ESTUDOS \\
URBANOS E \\
REGIONAIS \\
\end{tabular} & *-*** & Nacional & Gestão territorial metropolitana \\
\hline
\end{tabular}


PLANILHA DO PDUI

\begin{tabular}{|c|c|c|c|c|c|c|c|c|c|}
\hline \multirow{2}{*}{$\begin{array}{c}\text { REGlão } \\
\text { METROPOLITANA }\end{array}$} & \multicolumn{2}{|c|}{ POPULAÇĀOO(ANO 2017) } & \multirow{2}{*}{ SITUAÇĀOODOPDUI } & \multicolumn{2}{|c|}{ AUTORIDADE METROPOLITANA } & \multirow{2}{*}{$\begin{array}{l}\text { FUNDO DEDEEENVOLVIMENTO } \\
\text { MERROPOUTANO }\end{array}$} & \multirow{2}{*}{ OUTROSÓRGAOS } & \multirow{2}{*}{$\begin{array}{l}=\text { NORMA REGENTE DEPDL } \\
\text { ATUAL }\end{array}$} & \multirow{2}{*}{$\begin{array}{l}=\text { LINK DO ESTÁGIO, } \\
\text { ATUALL(LEGLLLTIVO } \\
\text { OU ADMINISTRATIV??) }\end{array}$} \\
\hline & $\begin{array}{c}\text { CAPITAL } \\
\text { (BGGE) }\end{array}$ & $\begin{array}{c}\text { REGGÄO } \\
\text { METROPOLITANA (FNEM) }\end{array}$ & & NOME & TIPO DE ENTIDADE & & & & \\
\hline Aracajü & 650.106 & 951.073 & Năo iniciado & $\begin{array}{l}\text { Seinfra- Secretaria } \\
\text { de Estado de } \\
\text { Infraestrutura e do } \\
\text { Desenvolvimento } \\
\text { Urbano }\end{array}$ & órgão estadual & & $\begin{array}{l}\text { Grupos de Trabalho Intersecretarias } \\
\text { (GT) composto po SEPLAG, } \\
\text { SEINFRA, SEED, PGE assim como } \\
\text { por procuradores dos municipios } \\
\text { que compöem a regiäo } \\
\text { metropolitana } \\
\text { <http://www.seinfra.se.gov.brinindex.p } \\
\text { hp?pag=88id=28cod=724> }\end{array}$ & 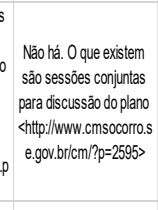 & $\begin{array}{l}\text { O projetto apresenttado } \\
\text { pelo Procurador Geral } \\
\text { Pedro Dias não está } \\
\text { disponivel na internet }\end{array}$ \\
\hline Belém & 1.452.275 & 2.441 .761 & näo foi effetivamente iniciada & $\begin{array}{l}\text { Secretaria de Estado } \\
\text { de Desenvolimento } \\
\text { Urbanoo Obras } \\
\text { Públicas (Sedop) }\end{array}$ & & & & & 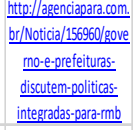 \\
\hline Boa Vista & 332.020 & 393.627 & $\begin{array}{l}\text { OPlano de Desenvolvimenti Urbano Integrado - } \\
\text { PDUl encontra-se em fase de estudo e } \\
\text { implantaçãa }\end{array}$ & $\begin{array}{l}\text { Secretaria de Estado } \\
\text { de Aticulaçäo } \\
\text { Municipal ePollica } \\
\text { Urbana - SEAMPU }\end{array}$ & órgäo estadual & & 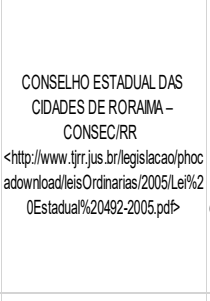 & 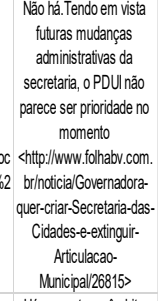 & \\
\hline Cuntiba & 1.908 .359 & 3.572 .326 & EMfase de elaboraçăo do Termo de Referêncila & 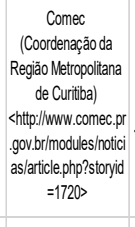 & $\begin{array}{c}\text { Autarquia vinculada à Secretaria de } \\
\text { Estado do Desenvolvimento Urbano } \\
\text {-SEDU } \\
\text { <http://www.desenvolvimentourbano. } \\
\text { pr.gov.bri> }\end{array}$ & $\begin{array}{l}0 \text { Estado participarai com 40\% e os } \\
\text { municipios com } 55 \% \text { dos recursos de } \\
\text { custeio complementares, sendo que } \\
\text { entre os municípios, Curitiba participaria } \\
\text { com 24,58\% e Quarro Barras participaria } \\
\text { com 0,74\% desses recursos } \\
\text { complementares. }\end{array}$ & $\begin{array}{c}\text { Secretaria de Estado do } \\
\text { Desenvolimimento Urbano - SEDU }\end{array}$ & $\begin{array}{l}\text { Há somente no âmbito } \\
\text { administrativo o Plano de } \\
\text { Desenvolimento } \\
\text { Integrado da RMC de } \\
\text { 2006, que será usado de } \\
\text { base para o Termo de } \\
\text { Referência que será } \\
\text { enviado à casa legislativa } \\
\text { estadual. }\end{array}$ & $\begin{array}{l}\text { hitp://www.comec.pr.g } \\
\text { ov.br/modules/conteud } \\
\text { olconteudo.php? ?onte } \\
\text { udo }=62\end{array}$ \\
\hline Florianópolis & 485.838 & 1.172.076 & Năo iniciado & SUDERF & autarquia de regime especial & $\begin{array}{l}\text { Há proposta para criaçăa do FDM e de } \\
\text { Conseho Fiscal }\end{array}$ & & $\begin{array}{l}\text { LC n }{ }^{\circ} 63612014-\text { RMFe } \\
\text { SUDERJ }\end{array}$ & $\begin{array}{c}\text { http://www.spg.sc.gov. } \\
\text { bril }\end{array}$ \\
\hline Fortaleza & 2.627 .482 & 4.051 .744 & $\begin{array}{l}\text { em fase de elaboraçăo prévia ao } \\
\text { encaminhamento ao Poder Legislativo. }\end{array}$ & $\begin{array}{c}\text { Gabinete do } \\
\text { Governador e pela } \\
\text { Secretaria das } \\
\text { Cidades, como o } \\
\text { apoio da Assembleia } \\
\text { Legislativa, por meio } \\
\text { do Instituto de } \\
\text { Estudos e Pesquisas } \\
\text { sobre o } \\
\text { Desenvolvimento do } \\
\text { Estado do Ceará } \\
\text { (NESP) }\end{array}$ & & & & & $\begin{array}{l}\text { hitps://Www.al.ce.gov. } \\
\text { brrindex.phplutimas- } \\
\text { noitciaslitem/686866- } \\
\text { 2509gm-01-inesp }\end{array}$ \\
\hline Goiânia & 1.466 .105 & 2.493.792 & Em fase de elaboraçăa & $\begin{array}{c}\text { Conselho de } \\
\text { Desenvwolimento da } \\
\text { Regäa Metropolitana } \\
\text { de Goiânia }\end{array}$ & Conselho metropolitano & Năoh há inorormaçăo & $\begin{array}{c}\text { Universidade Federal de } \\
\text { Goiás (UFG), em parceria com a } \\
\text { Fundaçäo de Apoio à Pesquisa } \\
\text { (Funape) }\end{array}$ & $\begin{array}{l}\text { Nắo há. O conselho foi } \\
\text { instituido pela LCp } \\
\text { 139/2018 }\end{array}$ & $\begin{array}{l}\text { hitp://www.secima.go. } \\
\text { gov.br }\end{array}$ \\
\hline Joä́ Pessoa & 811.598 & 1.193.095 & Năo iniciado & $\begin{array}{c}\text { Secretaria Estadual } \\
\text { de Planejamentio e } \\
\text { Gestäolsecretaria de } \\
\text { infraestrutura }\end{array}$ & órgão estadual & Năo há informaçăo & & năo há & \\
\hline Macapá & 474.706 & 610.564 & Năo inciciado & $\begin{array}{c}\text { Secretania de Estado } \\
\text { do Desenvolimento } \\
\text { das Cidades (SDC) } \\
\text { <htitps://Www.portal.a } \\
\text { p.gov.brestruturalsec } \\
\text { retaria-de-estado-do- } \\
\text { desenvolimento-das- } \\
\text { cidades> }\end{array}$ & órgăo estadual & & $\begin{array}{l}\text { Grupo de Trabalho (GT) } \\
\text { <htps:/www.pootal.ap.gov.br/noticial } \\
\text { 2302/gruppo-de-trabalho-trata-da- } \\
\text { regulamentacao-da-regiao- } \\
\text { metropolitana-de-macapa> }\end{array}$ & al & \\
\hline Maceió & 1.029 .129 & 1.304.497 & Năo iniciado & $\begin{array}{l}\text { SEPLAG-Secretaria } \\
\text { de Estado do } \\
\text { Planjamento, } \\
\text { Gestãoe Patrimônio }\end{array}$ & órgão estadual & não há previsão no momento & & $\begin{array}{l}\text { LC18/1998 dispōe sobre } \\
\text { a região metropolitana de } \\
\text { Naceió }\end{array}$ & \\
\hline Manaus & 2.130 .264 & 2.488 .336 & Năo iniciado & $* * *$ & $* * * *$ & $* \because * *$ & $* * *$ & $* * *$ & $* * * *$ \\
\hline Natal & 885.180 & 1.596.104 & Em fase de elaboraçăa & 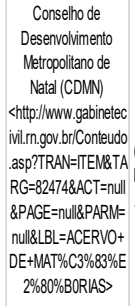 & 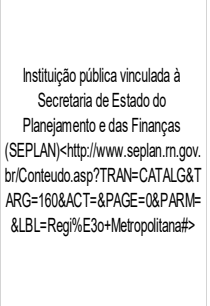 & $\begin{array}{l}\text { Há uma expressiva dependếncia das } \\
\text { receitas correntes } \\
\text { às transferências intergovernamentiais, } \\
\text { especialmente as } \\
\text { originadas da Uniäo e da Estado. Essa } \\
\text { dependêncial dimninuiu } \\
\text { um pouco em } 2005\end{array}$ & $\begin{array}{l}\text { Secretaria de Estado do } \\
\text { Planejamento e das Finanças } \\
\text { (SEPLAN) }\end{array}$ & $\begin{array}{l}\text { Há somente no âmbito } \\
\text { administrativo o PLANO } \\
\text { DE } \\
\text { DESENVOLVINENTO } \\
\text { SUSTENTÁVEL DA } \\
\text { REGIÄO } \\
\text { METROPOLTANA DE } \\
\text { NATAL - NATAL } \\
\text { METRÓPOLE 2020, de } \\
2007\end{array}$ & $\begin{array}{l}\text { hitp://ladcon.m.gov.br/A } \\
\text { CERVO/seplan/DOC/ } \\
\text { DOCO0000000010421 } \\
\text { 1.PDF }\end{array}$ \\
\hline
\end{tabular}




\begin{tabular}{|c|c|c|c|c|c|c|c|c|c|}
\hline Palmas & 286.787 & 471.639 & Não iniciado & $\begin{array}{c}\text { Secretaria de } \\
\text { Habitaçää e } \\
\text { Desenvolimento } \\
\text { Urbano } \\
\text { <https://habitacao.to.g } \\
\text { ov.brinstitucionallapre } \\
\text { sentacaol> }\end{array}$ & órgäo estadual & & 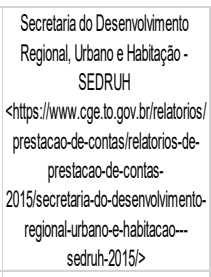 & $\begin{array}{l}\text { Năo há. O que existe é } \\
\text { somente o Projeto de } \\
\text { Desenvolvimento } \\
\text { Regional Integrado e } \\
\text { Sustentável (PDRIS) } \\
\text { ligado à Secretaria de } \\
\text { Meio Ambiente }\end{array}$ & $\begin{array}{l}\text { https://semanthto.gov.b } \\
\text { rl-projejto-de- } \\
\text { desenvolimentio- } \\
\text { regional-integrado-e- } \\
\text { sustentavel-pdris/ }\end{array}$ \\
\hline Porto Alegre & 1.484 .941 & 4.293 .050 & Em fase de elaboração & $\begin{array}{l}\text { Fundação Estadual } \\
\text { de } \\
\text { Planejamento } \\
\text { Metropolitanoe } \\
\text { Regional- } \\
\text { METROPLAN }\end{array}$ & fundaçäo estadual & Há proposta para criação do FDM & $\begin{array}{l}\text { 1) CDM-Conseho Deliberativo da } \\
\text { RM; 2) Gabiente de Governança da } \\
\text { RMPA }\end{array}$ & $\begin{array}{c}\text { LC } 0^{0} 13.85412011 \text { - CDM } \\
\text { e GG-RIPA }\end{array}$ & $\begin{array}{l}\text { http://www.metroplan.r } \\
\text { s.gov.brimsgg }\end{array}$ \\
\hline Porto Velho & 519.436 & 544.702 & Não iniciado & $\begin{array}{l}\text { SEDES-Secretaria } \\
\text { de Estado do } \\
\text { Desenvolvimento } \\
\text { Econônico e Social }\end{array}$ & órgão estadual & & $\begin{array}{l}\text { Näo há. É RM criada muito } \\
\text { recentemente. }\end{array}$ & Não há. & \\
\hline Recife & 1.633 .697 & 3.965 .699 & $\begin{array}{c}\text { Em fase de contratação da empresa lictiada } \\
\text { para elaboraçăao do PDUI }\end{array}$ & $\begin{array}{c}\text { CONDEPEFFIDEM- } \\
\text { Agência Estadual de } \\
\text { Planejamento } \\
\end{array}$ & Autarquia & $\begin{array}{l}\text { Previsão da instittuiçäo do FUNDERM- } \\
\text { Fundo da Regiäo Metroplitana do Recife. }\end{array}$ & SGM- Sistema Gestor Metropolitano & $\begin{array}{l}\text { 1998- Plano Diretor da } \\
\text { Regääo Metrooolitana }\end{array}$ & $\begin{array}{l}\text { http://www.condepefid } \\
\text { em.pe.gov.briweblcon } \\
\text { depe-fidem }\end{array}$ \\
\hline $\begin{array}{l}\text { Regiäo Itegradad de } \\
\text { Desenvolvimento da } \\
\text { Grande Teresina }\end{array}$ & 850.198 & 1.204 .397 & Em fase de elaboraçãa & $\begin{array}{c}\text { SEMPLAN- } \\
\text { Secretaria Municipal } \\
\text { de Planejamento } \\
\text { <htpp://semplan.teresi } \\
\text { na.pigovibriequipel> }\end{array}$ & órgão municipal & $\begin{array}{c}\text { empréstimo de US\$ } 45 \text { milhôes junto ao } \\
\text { Banco de Desenvovimentio da América } \\
\text { Latina (CAF) }\end{array}$ & $\begin{array}{l}\text { Conselhode Desenvolwimento } \\
\text { Urbano - CDU }\end{array}$ & $\begin{array}{c}\text { Programade } \\
\text { Desenvolvimento Urbano } \\
\text { Integrado - Teresina } \\
\text { Sustentável }\end{array}$ & 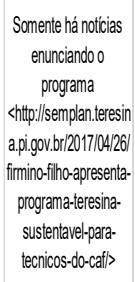 \\
\hline Rio de Janeiro & 6.520 .266 & 12.377 .505 & 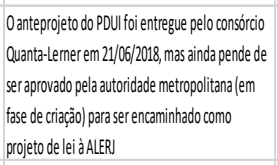 & $\begin{array}{l}\text { Agência Executiva da } \\
\text { Regiäo Metropolitana } \\
\text { do Riode Janeiro (em } \\
\text { fase de criaçăo - PL } \\
\text { estadual nn 10/2015) }\end{array}$ & órgãointerinstitucional & Há proposta de criaģão no PLn! 10/2015 & $\begin{array}{l}\text { Câmmara Metropolitana de Integraçäo } \\
\text { Governamental (criada em 2014) }\end{array}$ & & $\begin{array}{l}\text { http://www.modelaram } \\
\text { etropole.com.br }\end{array}$ \\
\hline Salvador & 2.953 .986 & 4.015 .205 & $\begin{array}{c}\text { Termo de referência em processo de finalização } \\
\text { para posterior lançamentio de edital de } \\
\text { concorerência pública para a elaboraçäao do PDUI. }\end{array}$ & $\begin{array}{l}\text { EMRMS- Entidade } \\
\text { Metropolitana da } \\
\text { Regiäo Metropolitana } \\
\text { de Salvador }\end{array}$ & $\begin{array}{l}\text { Autarquia Intergovernamental de } \\
\text { Regime Especial. Composta por } \\
\text { Colegiado Metropolitano, Comitê } \\
\text { técnico, Conselho Participativo, } \\
\text { Secretário Geral. }\end{array}$ & 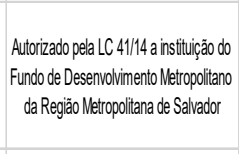 & $\begin{array}{l}\text { SEDUR-Secretaria Municipal de } \\
\text { Desenvolvimento e Urbanismo }\end{array}$ & $\begin{array}{l}\text { Plano metropolitano de } \\
\text { 1982, elaborado pela } \\
\text { Companhia de } \\
\text { Desenvolvimento Urbano } \\
\text { (Conder) }\end{array}$ & $\begin{array}{l}\text { httpp//www.emmms.ba. } \\
\text { gov.bript- } \\
\text { brlcontentportal- } \\
\text { informacao-web }\end{array}$ \\
\hline São Luís & 1.091 .868 & 1.443 .242 & 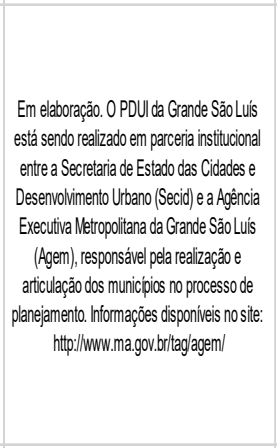 & 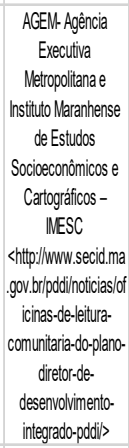 & órgão estadual & 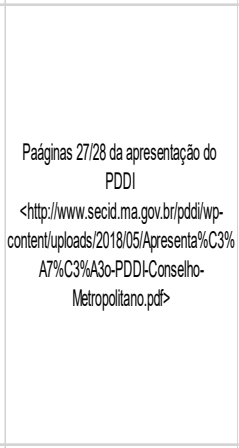 & $\begin{array}{l}\text { Secretaria de Estado das Cidades e } \\
\text { Desenvolvimento Urbano - SECD }\end{array}$ & $\begin{array}{c}\text { Apresentaçäo do } \\
\text { Diagnóstico do Plano } \\
\text { Diretor de } \\
\text { Desenvolvimento } \\
\text { Integrado da Regiäo } \\
\text { Netropolitana da Grande } \\
\text { São Luís ao Conselho } \\
\text { Metropolitano } \\
\text { <http://www.secid.ma.gov } \\
\text { bripddal/mgsl/> }\end{array}$ & $\begin{array}{l}\text { http///www.secid.ma.g } \\
\text { ov.br/pddidocumentos } \\
\text { / }\end{array}$ \\
\hline São Paulo & 12.106 .920 & 21.391 .624 & Em fase de elaboração & ENPLASA & $\begin{array}{l}\text { Instituição pública vinculadaà à } \\
\text { Secretaria Estadual da Casa Civil }\end{array}$ & $\begin{array}{c}\text { Fundo Metropolitano de Financiamentio e } \\
\text { Investimentos }\end{array}$ & $\begin{array}{l}\text { 1) Conselho de Desenvolvimento da } \\
\text { RMSP; 2) Conseho Consultivo da } \\
\text { RMSP }\end{array}$ & $\begin{array}{c}\text { LC n }{ }^{0} 1.139 / 2011-R M S P \\
\text { eCD-RMSP }\end{array}$ & $\begin{array}{l}\text { https://hww.pduis.sp.go } \\
\text { v.br/mspl }\end{array}$ \\
\hline Vitória & 363.140 & 1.960 .213 & $\begin{array}{l}\text { Aprovado pela Lei Complementare estadual } n^{\circ} \\
\qquad 8722017\end{array}$ & $\begin{array}{l}\text { Conselho } \\
\text { Metropolitano de } \\
\text { Desenvolvimento da } \\
\text { Grande Vitória } \\
\text { (COMDEVT) }\end{array}$ & Conselho metropolitano & $\begin{array}{c}\text { Fundo Metropolitano de Desenvolvimento } \\
\text { da Grande Vitória }\end{array}$ & Instituto Jones dos Santos Neves & $\begin{array}{l}\text { Lei Complementar } \\
\text { estadual n } 87222017\end{array}$ & $\begin{array}{l}\text { https://planometropolit } \\
\text { ano.es.gov.br }\end{array}$ \\
\hline $\begin{array}{c}\text { Regiäo Integrada de } \\
\text { Desenvolvimento do } \\
\text { Distrito Federale } \\
\text { Entorno-RIDE }\end{array}$ & 3.039 .444 & 4.373 .841 & Năo inciciado por näo ser obrigatório para RIDE & & & & & & \\
\hline Belo Horizonte & 2.523 .794 & 5.314 .930 & Concluido & $\begin{array}{c}\text { Consetho } \\
\text { Deliberativo da RMBH }\end{array}$ & & & & $\begin{array}{c}\text { Projeto de Lei } \\
\text { Complementar (PLC) } \\
74 / 17\end{array}$ & $\begin{array}{c}\text { <htps://Www.almg.gov } \\
\text { brlatividade_parlamen } \\
\text { tartramitacao_projetos } \\
\text { linterna.htm|l?a=2017\& } \\
n=7481=P L C>\end{array}$ \\
\hline Cuiabá & 590.118 & 1.005 .690 & Concluido & & & & & 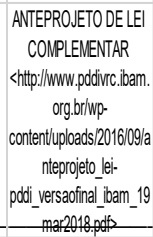 & $\frac{\text { http://www.pddivrciba }}{\text { m.org.,br/ }}$ \\
\hline
\end{tabular}


${ }^{1}$ Lei Complementar no 14/73 instituiu 8 regiões metropolitanas: Belo Horizonte, São Paulo, Porto Alegre, Curitiba, Salvador, Recife, Fortaleza, Belém. Com a fusão dos Estados da Guanabara e do Rio de Janeiro, foi criada a Região Metropolitana do Rio de Janeiro, por meio da Lei Complementar no 20/74.

2 Tanto a Constituição Federal de 1967 quanto a emenda constitucional no 01/1969 (normalmente chamada de Constituição de 1969) já continham previsão similar, respectivamente nos arts. 157, § 10 e 164 .

${ }^{3}$ Sobre a proteção constitucional dos entes federativos no âmbito das regiões metropolitanas, cf. STF, ADI 1842, Relator Min. Luiz Fux, Relator p/ Acórdão Min. Gilmar Mendes, Tribunal Pleno, julgado em 06/03/2013, publicado em 16/09/2013.

${ }^{4}$ Brasil. (2004). Inclui diretrizes para a Política Nacional do Planejamento Regional Urbano, cria o Sistema Nacional de Planejamento e Informações Regionais Urbanas e dá outras providências. Brasília: Diário Oficial da União. Recuperado em 12 de junho de 2018, de http://www.camara.gov.br/proposicoesWeb/fichadetramitacao?idProposicao=251503.

${ }^{5}$ Desde que o Município se enquadre nas hipóteses do art. 41. Sobre a impossibilidade dessa exigência ser direcionada a outros Municípios, cf. STF, ADI 826, Relator Min. Sydney Sanches, Tribunal Pleno, julgado em 17/09/1998, publicado em 12/03/1999.

${ }^{6}$ Art. 2ㅇ São Poderes da União, independentes e harmônicos entre si, o Legislativo, o Executivo e o Judiciário.

7 Art. 18. A organização político-administrativa da República Federativa do Brasil compreende a União, os Estados, o Distrito Federal e os Municípios, todos autônomos, nos termos desta Constituição.

${ }^{8}$ Art. 25. Os Estados organizam-se e regem-se pelas Constituições e leis que adotarem, observados os princípios desta Constituição. § 3으 Os Estados poderão, mediante lei complementar, instituir regiões metropolitanas, aglomerações urbanas e microrregiões, constituídas por agrupamentos de municípios limítrofes, para integrar a organização, o planejamento e a execução de funções públicas de interesse comum.

${ }^{9}$ Art. 32. O Distrito Federal, vedada sua divisão em Municípios, reger-se-á por lei orgânica, votada em dois turnos com interstício mínimo de dez dias, e aprovada por dois terços da Câmara Legislativa, que a promulgará, atendidos os princípios estabelecidos nesta Constituição.

${ }^{10}$ Art. 19. Respeitada a vedação de divisão em Municípios estabelecida no caput do art. 32 da Constituição Federal, o Distrito Federal poderá integrar região metropolitana ou aglomeração urbana, aplicando-se a ele o disposto no art. 40 e nas demais disposições desta Lei.

Razões dos vetos: “Ao tratar de regiões metropolitanas, aglomerações urbanas e microrregiões, a Constituição faz referência, em seu art. 25, § 3o, a agrupamento de Municípios. Neste sentido, as inclusões no escopo do Estatuto da Metrópole de território de um único Município isolado e do Distrito Federal não encontrariam amparo constitucional. Em relação ao Distrito Federal, o instrumento de cooperação federativa adequado é a Região Integrada de Desenvolvimento Econômico - RIDE, prevista no art. 43 da Constituição. Está já foi, inclusive, criada pelo Decreto no 2.710, de 4 de agosto de 1998 - substituído pelo Decreto no 7.469, de 4 de maio de 2011 - que regulamenta a Lei Complementar no 94, de 19 de fevereiro de 1998". 
11 < http://semplan.teresina.pi.gov.br/2017/04/26/firmino-filho-apresenta-programa-teresina-sustentavelpara-tecnicos-do-caf/> acesso em 21 de junho de 2018.

$12<$ http://www.secid.ma.gov.br/pddi/rmgsl/> acesso em 21 de junho de 2018.

${ }^{13}<$ http://www.rj.gov.br/web/segov/exibeconteudo?article-id=7307368> acesso em 30 de junho de 2018.

${ }^{14}<$ https://www.pdui.sp.gov.br/rmsp/> acesso em 21 de junho de 2018.

${ }^{15}<$ http://www.cmsocorro.se.gov.br/cm/?p=2595> acesso em 21 de junho de 2018.

${ }^{16}<$ https://semarh.to.gov.br/-projeto-de-desenvolvimento-regional-integrado-e-sustentavel-pdris/> acesso em 21 de junho de 2018.

${ }^{17}<$ https://www.almg.gov.br/atividade parlamentar/tramitacao projetos/interna.html?a=2017\&n=74\&t=PLC> acesso em 21 de junho de 2018.

${ }^{18}<$ https://planometropolitano.es.gov.br/> acesso em 21 de junho de 2018.

\section{Referências bibliográficas}

ANTONUCCI, Denise et al. UN-Habitat: das declarações aos compromissos. Denise Antonucci, Angélica Benatti Alvim, Silvana Zioni e Volia Costa Kato. São Paulo: Romano Guerra, 2010.

COSTA, M. A., TSUKUMO, I. T. L. (org.). 40 Anos de Regiões Metropolitanas no Brasil. IPEA/Brasília, 2013.

GARSON, Sol. Regiões metropolitanas - diversidade e dificuldade fiscal da cooperação. Cadernos Metrópole, São Paulo, v. 11, n. 22, pp.435-451, jul/dez 2009.

MONTE-MÓR, Roberto Luís. A questão urbana e o planejamento urbano-regional no Brasil contemporâneo. In: C. C. Diniz \& M. B. Lemos (Eds.). Economia e Território. Belo Horizonte: UFMG, 2005, pp. 429-446.

OLSON, Mancur. A lógica da ação coletiva: os benefícios públicos e uma teoria dos grupos sociais. São Paulo: EDUSP, 1965.

SANTOS, Angela M. S. P. Políticas Sociais em Xeque: Impactos da crise sobre as finanças municipais. Artigo apresentado no XV Seminário Internacional da Rede Iberoamericana de Investigadores de Globalização e Território, no Grupo II (Globalização, financeirização, crise global, nova geografia da urbanização e metamorfose urbana). Santiago, Chile, nov 2018. 
. Post-Constitutional Urban Policy: the experience of the Municipality of Rio de Janeiro. Política Urbana Pós-Constitucional: a experiência do Município do Rio de Janeiro. Revista de Estudos Urbanos e Regionais/ANPUR, V. 19, N.1, 2017.

UN-Habitat: The Vancouver Declaration on Human Settlements. Habitat I. 1976. Disponível em: $<$ http://mirror.unhabitat.org/downloads/docs/TheVancouverDeclarationOnHumanSettlements.pdf >. Acesso em: 08 ago 2018.

.The Vancouver Action Plan. Habitat I. 1976. Disponível em: <http://habitat76.ca/2016/06/unhabitat-1976-vancouver-declaration-action-plan/>. Acesso em: 08 ago 2018.

. Istanbul Declaration on Human Settlements. Habitat II. 1996. Disponível em: <https://unhabitat.org/wp-content/uploads/2014/07/The-Habitat-Agenda-Istanbul-Declaration-onHuman-Settlements-20061.pdf>. Acesso em: 08 ago 2018.

. A new urban paradigm: pathways to sustainable development. Vol. 13, Issue N.3. December 2016. Acesso em: 08 ago 2018.

- New Urban Agenda. Habitat III. 2017. Disponível em: <http://habitat3.org/wpcontent/uploads/NUA-English-With-Index-1.pdf>. Acesso em: 08 ago 2018. 